\title{
LAS ACTITUDES MENTALES DE LOS BARCELONESES DEL PRIMER TERCIO DEL SIGLO XIV
}

\author{
SUMARIO* \\ I. La idea de la muerte: 1. Causas que mueven a testar.- 2. Elección de \\ sepultura.- 3. Liturgia y ritos funerarios: banquetes de difuntos y aniversarios.- \\ II. Obras pías y limosnas: 1. Pobres vergonzantes.- 2. Redención de cautivos.- \\ III. Muchachas casaderas.- 4. Hospitales.- 5. Presbiteratos. 3. Reconocimiento de \\ deudas.
}

\section{INTRODUCCIÓN}

Uno de los aspectos más interesantes que puede presentar el estudio de un grupo humano, a lo largo de un período histórico determinado, lo constituye sin duda el comportamiento adoptado por sus miembros a la hora de enfrentarse al final de sus días. Es evidente que la toma de conciencia ante la seguridad de la muerte provoca, en mayor o menor medida, una reacción anímica concatenada que se traduce en una serie de manifestaciones que van desde el arrepentimiento -acompañado de fuertes dosis de temor- hasta una liberalidad exagerada que no puede disimular su verdadero trasfondo expiatorio.

El sentimiento de la muerte obliga, pues, a participar en un juego que nadie se atreve a rechazar, ya que todos aquellos que disponen de bienes materiales se enfrentarán al problema en el momento mismo de plasmar ante notario sus últimas voluntades. El testamento adquiere así unas dimensiones que rebasan el simple marco jurídico y se convierte en el mecanismo idóneo para mitigar el rigor de la justicia divina, concediendo al causante la oportunidad de purificar su alma mediante la asignación de legados píos, celebración de misas, institución de aniversarios y beneficios eclesiásticos, liquidación de deudas y, en definitiva, reconocimiento de las injurias cometidas a lo largo de toda la vida.

Por tal razón, las escrituras de declaración de últimas voluntades se erigen en el

- Abreviaturas utilizadas: $\Lambda C \Lambda=$ Archivo de la Corona de Aragón; $\Lambda$ CB = Archivo Capitular de Barcelona; $B N=$ Biblioteca Nacional (Madrid); BV = Bernat de Vilarrúbia; C = Cancillería; CSIC = Consejo Superior de Investigaciones Científicas; $d / s$. = dimer/s; IMH = Instituto Municipal de Historia (Barcelona); lb/s. = libra/s.; $\mathrm{mb} / \mathrm{s}$. = morabetino/s.; ms. = manuscrito; MT = Manual de Testamentos (1300-1339); N = Notaría; reg. = registro; s/ss. $=$ sou/s. 
vehículo idóneo para el estudio de la mentalidad colectiva de un determinado grupo poblacional y suponen, por añadidura, una aportación sectorial a la construcción de la Historia Social. De ahí el valor, cuantitativo y cualitativo, de los testamentos registrados en el Manual de Bernat de Vilarrúbia, notario público de la Barcelona trecentista, que han sido utilizados como fuente documental de primera mano para analizar el ritual funerario y la disposición anímica de un buen número de ciudadanos de diversa condición '.

\section{LA IDEA DE LA MUERTE}

Una de las constantes preocupaciones de los barceloneses del primer tercio del siglo XIV es la certeza de que en el más allá deberán responder de sus actos ante el Creador, el cual obrará en consecuencia premiando a los inocentes y castigando ejemplarmente a los culpables con las atrocidades del infierno, pues la creencia en el Maligno, al igual que la idea de la muerte personificada en la dama de la guadaña, forma parte del legado espiritual de la población del Occidente medieval. En efecto, toda la literatura moralizadora de la Edad Media, así como las artes plásticas, reflejan una sincera preocupación por el destino que la Divinidad reserva a los que mueren impenitentes y tal creencia es común al conjunto de grupos étnicos que componen la población (cristianos, musulmanes y judíos). De esta manera, en el seno del colectivo se va a acentuar el instinto de salvación y se utilizarán todos los medios disponibles para enviar el alma al Paraíso, pero antes se requiere, como bien señala Manuel Riu, el trámite ineludible de la extinción de la vida y abandono del cuerpo exánime ${ }^{2}$. Esta idea del tránsito al más allá se desarrollará obsesivamente en la mentalidad colectiva del hombre bajomedieval, llegando a formar parte de su peculiar universo cultural ${ }^{3}$.

Es posible que esta preocupación por el futuro destino del alma genere un sentimiento de inseguridad entre la población, basado primordialmente en los tres enemigos del ser humano, la peste, el hambre y la guerra, que azotan y diezman a los habitantes de la ciudad y del campo de forma indiscriminada. Los barceloneses que nos han dejado sus testamentos empiezan a conocer las primeras amenazas de la peste ${ }^{4}$, y muchos de ellos han vivido en sus carnes el azote del

1 Se trata de un volumen depositado en el Archivo Capitular de Barcelona que registra un total de 150 testamentos y 6 codicilos formalizados entre los años 1300 y 1339 , período clave en la historia de la Ciudad Condal. Tiene un formato de $20 \mathrm{~cm}$. $\times 30 \mathrm{~cm}$. y consta de 200 folios, escritos por ambas caras. Se compone de 4 cuadernillos o pliegos y el papel es de algodón verjurado, de óptima calidad. La escritura es una semicursiva, que tiende en ocasiones a la cursiva aunque no llega a alterar la forma clásica de las letras.

2 Ver M. RIU, La vida, las costumbres y el amor en la Edad Media, Barcelona, Ed. Gassó, 1959, pp. 3536.

3 Es el momento en que las macabras «Danzas de la Muerten, por citar un ejemplo, adquieren su mayor difusión histórica y literaria.

4 En el bienio de 1333-1334, período de intensas y prolongadas sequías, se extiende la peste bubónica -o glánola- entre la población barcelonesa, como consecuencia inevitable del hambre y la miseria que se ha dejado sentir entre los estratos más humildes [Ver Datos Históricos sobre las epidemias de peste ocurridas en Barcelona (Memoria realizada por Ferrán, Viñas y Grau por encargo del Excmo. Ayuntamiento en 1907), «Documentos y Estudiosw, XV (Barcelona, 1965), pp. 371-372]. La mortandad causada por la epidemia ascendió a 10.000 habitantes, según las fuentes, lo cual representa aproximadamente un tercio de la población total de la ciudad y su 
hambre 'y han sufrido los calamitosos resultados de guerras y expediciones armadas (como la conquista de Murcia, la insurrección de Djerba, la hostilidad del sultanato abdaluadida, la toma de Cerdeña, el conflicto con Génova o las campañas de los almogávares) con todas sus secuelas sobre un gran número de ciudadanos, que han regresado a su tierra heridos o mutilados y que conservan en la memoria la imagen de aquéllos que nunca volverán a ver ya que perecieron en el camino o fueron reducidos a esclavitud.

Así pues, la población civil y religiosa bajomedieval ha heredado muchas lacras de sus antepasados, quienes parecen haberles transmitido a su vez el temor y la aprensión al fenómeno del tránsito al más allá, hasta el extremo de que la mayoría de cláusulas testamentarias sirven de excusa para iniciar un proceso de catarsis íntima que, pasando por la autoconfesión, intenta llevar a la salvación ${ }^{6}$.

El acto de la muerte de los individuos, en cualquier momento histórico y bajo circunstancias determinadas, ha sido tradicionalmente objeto de descuido por parte de la historiografía, preocupada en facilitar datos numéricos acerca de los fallecidos en el campo de batalla o a consecuencia de la peste, pero omitiendo voluntaria o involuntariamente las connotaciones mentales que la desaparición física produce siempre en el ánimo de aquellos que se enfrentan a la enfermedad o la vejez.

Hasta el momento la muerte, entendida como factor transformador de las estructuras económicas y sociales, ha sido el centro de atención de unos pocos especialistas, que constituyen una rara excepción '. Los historiadores de la demogra-

territorio jurisdiccional. Joan Francesc Boscà, ilustrado barcelonés del siglo XV, dice: En aquest any moriren de pestilencia e altres malalties moltes persones en la fiutat de Barchinona. E comenşaren les grans mortaldats un dimarts a XXVIII dies del mes de mars fins per tot lo mes d'agost après següent. E moriren-bi dins lo dit temps deu milia persones, car poques cases foren de la dita fiutat que algú no y moris o bi fos malalt. E moltes cases e obradors restaren buyts en la dita fiutat U.F. Boscà, Memorial Històric, a cura de J. Sobrequés, Barcelona, Associació de Bibliòfils de Barcelona, 1977, p. 58 (BN, ms. 1803, f. 169v)]. Un siglo después será el notario barcelonés Esteve Gilabert Bruniquer quien consigne esta cifra de víctimas de la peste: En l'any 1333 grans carestias y peste, per que en poc temps moriren més de deu milia bòmens [E.G. BRUNIQUER, Ceremonial dels Magnífichs Consellers y Regiment de la Ciutat de Barcelona, IV, a cura de F. Carreras Candi-B. Gunyalons, Barcelona, Impr. d'Henrich y \&, 1915, p. 319].

5 Tradicionalmente se habla del año 1333 como 10 mal any primer, aunque las crisis de subsistencia se producen ya desde principios de siglo de forma esporádica. Tenemos documentados algunos años de hambre y escasez, como 1302 y 1311, en los que falla el suministro de cereales a Barcelona y la carestía de alimentos provoca la adopción de medidas de urgencia por parte de la Corona y de los órganos del gobierno municipal [Ver E. SERRA, Els cereals a la Barcelona del segle XIV, "Alimentació i societat a la Catalunya Medieval», Barcelona, CSIC, 1988, pp. 71-107]. De cualquier modo, 1333 fue un año dramático ya que el hambre se adueña de la ciudad y se disparan los precios del trigo, provocando la protesta popular que acaba en saqueo y pillaje. Boscà nos explica así el curso de los acontecimientos: Dijous, a VIll del mes de desembre del dit any [1333], comenşà la gran fam e carestia en la ģiutat de Barchinona, car forment de Urgell e de Sicilia comenşà a pujar XXXV solidos la quartera e ondi a XX solidos. Edissapse a $X V$ de janer pujà forment a XXXXII solidos la quartera e ordi a XXIlll solidos la quartera. En lo dit any, per la carestia, fou avalot en Barchinona e robaren lo albercb d'en Aman Bernat, conseller, e d'en Bermat de Marimon, que no y deixaren res [J.F. BOSCA, Memorial Històric, p. 58 (BN, ms. 1803, f. 169r)].

6 Jean Delumeau califica esta época como los siglos de «la cultura del miedon U. DELUMEAU, La paura in Occidente (secoli XIV-XVIII). La città assediata, Torino, Società Editrice Internazionale, 1979, p. 42].

7 Últimamente el tema de la muerte ha sido analizado por cierto número de historiadores franceses con rigor y seriedad [Ver J. LE GOFF, Mentalidades, sensibilidades, actitudes (s. X-XIIl), "La Civilización del Occidente medieval», Barcelona, Ed. Juventud, 1969, pp. 433-487. M. VOVELLE, Mourir autrefois. Attitudes collectives devant la mort aux XVIle et XVIlle siècles, Paris, Éd. Gallimard, 1974. J. CHIFFOLEAU, La comptabilité de l'au-de-là. Les bommes, la mort et la religion dans la région d'Avignon à la fin du Moyen Afe (vers 1320-vers 1480), Rome, École 
fía, en general, acuden a las actas de defunción para articular sus estadísticas, lo cual no deja de ser convincente, pero no suelen servirse del contenido de las disposiciones testamentarias de los ciudadanos del pasado y los datos obtenidos adolecen así de la falta del contexto cultural que requiere la construcción de la Historia de las Actitudes Mentales.

El Manual de Testamentos de Bernat de Vilarrúbia, utilizado como fuente documental, se muestra pues con todo su valor ya que permite profundizar en la voluntad post mortem de los barceloneses del primer tercio del siglo XIV y clarifica espectacularmente lo que podríamos definir como «los signos externos del miedo al más allá»; es decir, legados de caridad, redención de cautivos, asistencia a los pobres, financiación de obras civiles y religiosas, institución de aniversarios y presbiteratos, etc. Y la información obtenida sirve, además, para ampliar el estado actual de nuestros conocimientos sobre la idiosincrasia de los individuos, desvelando paso a paso las causas que les mueven a testar, a elegir libremente su sepultura o a disponer con minuciosidad la liturgia que se seguirá en sus funerales.

\section{I.1 Causas que mueven a testar}

Las razones que inducen al hombre bajomedieval a formalizar su testamento no difieren excesivamente de las que siente la población de cualquier otro período histórico, comprendido el momento actual. Se trata de una serie de motivaciones que, en definitiva, no han variado desde que el testamento, en cualquiera de sus variantes (oral, escrito, ológrafo o nuncupativo), se constituye como el vehículo idóneo para ejercer el derecho a la libre disposición de bienes.

En líneas generales, los motivos que alegan los barceloneses de la época estudiada se pueden resumir en tres grandes grupos ${ }^{8}$ :

Française de Rome, 1980. Ph. ARIÈs, La muerte en Occidente, Barcelona, Ed. Argos Vergara, 1982]. Dentro de nuestras fronteras el interés por todo cuanto rodea las actitudes mentales ante la muerte se ha incrementado notablemente a partir de la década de los 80 [Ver M. RIU, Alguns costums funeraris de l'Edat Mitjana a Catalunya, *Acta/Mediaevaliaw, Annex 1, Barcelona, 1982, pp. 29-57. R. GARCíA CÁRCEL, La muerte en la Barcelona del Antiguo Régimen. Aproximación metodológica, «Actas del II Congreso de Metodología Aplicada a las Ciencias Históricasw, Santiago de Compostela, 1982, pp. 1-32 y, del mismo autor, Morir a la Barcelona del Barroc, "L'Avençw, 78 (Barcelona, 1985), pp. 58-59. J. RAMISA, La muerte y el más allá en la Barcelona de finales del siglo XIV y principios del XV. El mannal de testamentos de Gabriel Canyelles, Tesis de licenciatura inédita, Barcelona, 1985. O. LÓPEZ, La urgència de la salvació: les misses "post mortem», «L'Avenç», 78 (Barcelona, 1985), pp. 60-63. S. CLARAMUNT, La muerte en la Edad Media. El mundo urbano, «Acta/Mediaevaliaw, 7-8 (Barcelona, 1986-87), Pp. 205-218. E. MITRE, Lo proparación ante la muerte en torno a 1300 (Algunos elementos configuradores del cars moriendis en Occidente), Ilbidems, pp. 219-243].

8 Esta clasificación tripartita contempla los motivos que impulsan a los testadores barceloneses del Manual estudiado [Ver infra, Cuadro 1: Causas que mueven a testar]. No se analizan aquí las causas generales, algunas de ellas muy difundidas en otros momentos históricos. No debe extrañar, pues, el hecho de que las grandes pestilencias del siglo XIV no se citen como revulsivo a la hora de formalizar la escritura, ya que el último testamento se registra nueve años antes de la aparición de la Peste Negra en la Ciudad Condal [ACB, N, BV, MT, ff. 1 5v-16r], aunque la gran mortandad de los años 1333-1334 debe haber hecho mella en el espíritu de los barceloneses. Muchos de los causantes que formalizan la escritura a partir de lo primer mal any actúan sin duda influidos por los acontecimientos, pese a que no aluden directamente al hambre o la peste. Es evidente que un vaciado sistemático de las actas notariales conservadas en los diferentes archivos barceloneses pondría de manifiesto un fuerte incremento en el número de testamentos escriturados en los períodos epidemiales $(1334,1348,1351,1362-63,1371,1375$, etc.). El primer aviso de lo que se avecina aparece, sin embargo, en el catastrófico bienio de 1333-1334 [Ver supra, notas 4 y 5] y el Mammal estudiado se hace eco de esta situación ya que el número de testamentos aumenta espectacularmente a partir de 1333 y se dispara entre 1334- 1336. 
a.- problemas físicos y de salud (enfermedad, vejez, accidentes, traumatismos o lesiones graves)

b.- inminencia de viajes (expediciones guerreras o comerciales, peregrinación a lugares de culto, embajadas a cargo de la Corona o de la ciudad)

c.- lucubraciones mentales de orden ético-religioso (temor a la muerte, futilidad de las cosas terrenales, etc.).

Entre estos testadores priva el número de aquellos que se mueven a causa de la enfermedad y de la vejez, situándose a continuación los que invocan la certeza de una muerte segura $y$, por último, los que se disponen a emprender un desplazamiento en cualquiera de sus modalidades, actividad que entraña siempre un alto riesgo.

\begin{tabular}{|l|c|c|c|c|c|}
\cline { 2 - 6 } \multicolumn{1}{c|}{} & Hombres & Mujeres & Hombres & Mujeres & Total \\
\hline Enfermedad & 55 & 50 & 36.42 & $33 \cdot 11$ & 69.53 \\
\hline Lucubraciones & 22 & 11 & $14 \cdot 56$ & $7 \cdot 28$ & $21 \cdot 84$ \\
\hline Vejez & 5 & 4 & 3.31 & $2 \cdot 64$ & $5 \cdot 95$ \\
\hline Viajes & 4 & -- & $2 \cdot 64$ & - & $2 \cdot 64$ \\
\hline
\end{tabular}

\section{Cuadro 1: Causas que muevon a testar}

Las fuentes consultadas son suficientemente explicativas y muestran la proliferación de testadores que declaran encontrarse enfermos (egritudine detentus), aunque a menudo insisten en la posesión de sus facultades mentales (in meo tamen pleno sensu) pese a padecer algún tipo de dolencia (licet eger corpore), lo cual no empaña su entendimiento (et integra memoria et loquela existens). En ocasiones aluden a la gravedad de su estado (gravi egritudine detentus) pero nunca al cuadro clínico que presentan, lo cual nos suministraría una información precisa acerca de las causas más corrientes de mortalidad .

La condición social de los causantes enfermos se extiende a todas las clases y estamentos, como es lógico, y no excluye a ricos o pobres, clérigos o milites,

9 La excepción a la regla aparece en el testamento del rico mercader Guillem Sala, el cual se ve obligado a testar por nuncupación debido a la ceguera que padece. De todas formas, pese a la imposibilidad de ver con sus propios ojos asegura encontrarse en perfecto estado de salud física y mental: licet oculorum corporali visione carrems, corpore tamen et monte sanus... [ACB, N, BV, MT, ff. 125r-129r]. 
menestrales o ciutadans bonrats ${ }^{10}$. Nadie escapa a los zarpazos de la enfermedad y esta realidad mueve al conjunto de la ciudadanía, de forma unánime, a decidir el futuro destino de sus bienes y pertenencias materiales. Y en el momento mismo de testar desparece, o cuando menos pierde virulencia, la diferenciación social que les separa por cuanto todos muestran idéntico temor a morir sin reconocer sus deudas y siguen, en el campo mental, unas pautas de conducta significativamente colectivas".

La vejez constituye otra de las razones que lleva a los barceloneses a testar. Efectivamente, en la documentación se establece de forma clara la diferencia entre enfermedad (gravi egritudine oppresus) y ancianidad (licet corpore languens), lo que nos sitúa sin duda ante testadores que sienten próximo el final de sus días a causa de su avanzada edad ${ }^{12}$.

El número de aquéllos que no parecen estar enfermos, por otra parte, es relativamente elevado y representa el $21{ }^{\prime} 85 \%$ del total de testadores. Todos empiezan su declaración con disquisiciones más o menos extensas acerca de la futilidad de la vida, insistiendo en que no pueden predecir el final de sus días o repitiendo hasta la saciedad que ningún mortal eludirá su destino ${ }^{13}$. Y acto seguido proceden a cumplir con los aspectos eminentemente prácticos (elección de albaceas, cláusulas substitutorias, recomendaciones, etc.), con lo cual queda claro que intentan evitar que la muerte les sorprenda sin haber tenido ocasión de ordenar sus asuntos y nombrar herederos.

Un estudio en profundidad del status sociolaboral de los barceloneses que acuden al notario sin padecer aparentemente enfermedad alguna conduce inevitablemente a un callejón sin salida, pues entre ellos aparecen representantes de los milites, funcionarios reales, juristas, notarios, mercaderes, monjas, zapateros, marineros y barqueros, etc. El estado civil, además, presenta solteros, viudos y casados en

10 El abanico social de los testadores enfermos es muy amplio y queda reflejado en las actas notariales. Desde un humilde mestre d'obres como Pere Cases [ 1 bidem, ff. 92v- 93v] hasta el poderoso miles Guillem de Torrelles [Ibidem, ff. $174 \mathrm{v}-177 \mathrm{r}$ ], pasando por todo tipo de menestrales y representantes del mundo laboral y mercantil como el picapedrer Bernat Collet [Ibidem, ff. 133r-134r] o el sabater Pere Despuig [Ibidem, ff. 35v-36v], sufren alguna dolencia que les mueve a testar.

11 Es muy similar el proceso mental que traslucen los testamentos de los acaudalados mercaderes ultramarinos Bernat Carnicer [lbidem, ff. 123v-125r] y Gilabert de Malla [Ibidem, ff. 134r-135v]; de los cavallers Guillem de Tort [1bidem, f. 24r] y Guillem de Viladecavalls [Ibidem, ff. 64v-67v]; de la influyente Brunissenda de Cervelló, perteneciente al clan vizcondal de los Cardona [lbidem, ff. 29v-32r]; de los miembros de las familias del patriciado urbano, como Jaume Gruny [1bidem, ff. 121r-123v]; de los presbíteros Ferrer Huguet [1bidem, ff. 141r-142r] y Guillem Martorell [lbidem, ff. 148r-1 50v], beneficiados respectivamente en Santa Eulàlia del Camp y en la Catedral; del fuster Pere Torrent [Ibidem, ff. 19v-20r] o del judío Aarón Ravel [Ibidem, ff. 7r-8r]; pese a los desequilibrios de riqueza y prestigio social que cada uno de ellos ostentó a lo largo de su vida.

12 Es el caso, por ejemplo, de Pere Refechs, miembro de una acreditada familia de notarios y juristas [lbidem, ff. 16r- 17v] o de Bernarda, esposa de Pere Gras, perteneciente al círculo mercantil de la ciudad [lbidem, ff. 70v-72v], y sus palabras no deben ser un eufemismo ya que ambos tienen hijos y nietos y, además, el primero está casado en segundas nupcias y los hijos habidos de su anterior matrimonio ya son adultos.

13 El estilo de estos razonamientos es muy similar. En ocasiones se utiliza una simbología bastante simple, que alude a la pérdida de materia corpórea y al tránsito al más allá, como: Attendens quod nulli mortalium est notus terminus finis sui; nil morte certius nil tamen incertius bora mortis; attendens quad illa que babent visibilem essentiam tendunt visibiliter ad non esse, etc. 
primeras o segundas nupcias de ambos sexos, aunque los varones doblan numéricamente a sus conciudadanas ${ }^{14}$.

Respecto a aquellos que deciden formalizar sus últimas voluntades ante el riesgo que supone emprender viaje hacia tierras lejanas, no constituye ninguna sorpresa el hecho de que se trate en su totalidad de varones. El destino de estos desplazamientos suele estar íntimamente ligado a la política exterior de Jaume II ${ }^{15}$, a los deseos de peregrinar a los santos lugares ${ }^{16} \mathrm{o}$ a causa de gestiones comerciales ".

Quizás uno de los aspectos más destacables, a la hora de analizar las causas que mueven a testar a los barceloneses de cualquier estamento y condición, se encuentra en el hecho de que ninguna de las mujeres que aparecen en el Manual invoca los peligros del parto, pese a que este trance ocasionaba una gran mortandad ${ }^{18}$. El temor que los rigores de dar a luz imponen entre la población femenina barcelonesa es motivo, en efecto, de no demorar el acto de testar ante notario público. Un ejemplo significativo es el de la propia reina Blanca, la cual dispone sus últimas voluntades en 1308 antes del nacimiento de Ramón Berenguer, penúltimo de sus hijos, y dice actuar ob multa pericula que emergunt femineo sexui ante partum et in partum similiter et post partum ${ }^{19}$.

\section{I.2 La libre elección de sepultura}

Los barceloneses del primer tercio del siglo XIV gozan, sin lugar a dudas, del

14 Entre las 11 mujeres que testan sin la urgencia provocada por la enfermedad se encuentran 6 viudas, 1 soltera, 2 casadas y las 2 únicas religiosas del Manual, que profesan en la Orden Tercera de San Francisco. Este último caso no plantea problemas de interpretación ya que el hecho de ingresar en la Orden franciscana, con la obligación de prestar voto de pobreza, impulsa a ambas monjas a renunciar a sus bienes materiales en beneficio de la comunidad a que pertenecen [Ibidem, f. $45 \mathrm{r}-\mathrm{v}$ ].

is En 1309 el noble Roger de Castellcir se dispone a participar en la campaña de Granada, por ejemplo, y ordena minuciosamente un largo testamento en el que destina la enorme suma de 12.000 ss. para liquidar deudas. Ignoramos la fecha del fallecimiento de este cavaller y resultaría interesante saber si consiguió sobrevivir a la expedición, que acabó en fracaso. En enero de 1310, medio año después de su testamento, la milicia es licenciada a las puertas de Almería y recibe la orden de repatriarse a sus expensas, iniciándose así una penosa retirada protagonizada por los restos de un ejército constantemente hostigado por las tropas nazaríes. El propio Roger explica que las razones que le inducen a participar en la campaña son «luchar por la fé católica y, de paso, prestar su apoyo al Ilustrísimo rey de Aragón» [16idem, ff. 24v- 27r].

16 Jaume Déu se prepara, en julio de 1317, para peregrinar a Santiago de Compostela y muestra su preocupación ante los numerosos peligros que entraña su viaje. Desconocemos su condición social, aunque sabemos que se trata de un individuo de edad madura pues tiene nietos. De cualquier modo la intención del peregrino queda bien reflejada en las primeras líneas del testamento, donde dice sin ambages que desea fervientemente visitar la ecclesiam Sancti lacobi Compostellae [lbidem, ff. 87r-88r].

17 En general no se especifica este tipo de actividad, aunque el contexto del testamento parece indicarlo. Tanto los albaceas como los parientes y amigos pertenecen a los ambientes mercantiles de Barcelona. Un ejemplo de la parquedad de información en este sentido es el testamento del joven Bernat Julià, formalizado en 1320 [Ibidem, f. 8v].

18 Pese a lo dicho se adivina que la inminencia del parto es la causa que mueve, por ejemplo, a Bartomeva, hija y heredera del acomodado notario Miquel Antiga, la cual acaba de contraer matrimonio y está embarazada de su primer hijo. Sin duda que el caso de Bartomeva es similar al de otras testadoras, que hablan de su embarazo y detallan las substituciones hereditarias pertinentes que entrarán en vigor si se da la circunstancia de que el futuro hijo no llega a nacer o muere en la niñez [lbidem, f. 113r].

19 Como es sabido la aprensión de Blanca de Anjou no tuvo consecuencias, pero dos años después falleció al nacer la infanta Violante. El monarca catalanoaragonés quedó viudo y a cargo de la educación de diez hijos menores 
derecho a elegir libremente el cementerio donde desean ser inhumados, lo cual ordenan indefectiblemente en las primeras líneas del testamento. En efecto, tras la intitulación, la invocación y la designación de albaceas, todos sin excepción proceden a ejercer este derecho y acto seguido establecen una cantidad en metálico para que los responsables liquiden el importe de los gastos derivados del entierro y los funerales. La cuantía de esta suma es difícil, en muchos casos, de precisar ya que no se destina solamente a tal efecto, sino que comprende de forma global la satisfacción de diversos conceptos (deudas domésticas, legados pro anima, etc.) ${ }^{20}$.

A la hora de elegir sepultura se advierte una clara preferencia por los cementerios de las iglesias y parroquias de la ciudad ${ }^{21}$. Un pequeño número de testadores se decide, sin embargo, por las instituciones religiosas situadas lejos de la urbe, decantándose obviamente por las parroquias de sus lugares de origen, mientras que otros se inclinan por reposar eternamente en iglesias ubicadas en las distintas partidas que componen la borta $i$ el vinyet (Granada, Olivera Rodona, Bederrida, Cubells, Llepaolles, Cantallops, Vinyals, etc.). Las necrópolis, antiguamente emplazadas lejos de la ciudad, han pasado ya a ser un elemento habitual del paisaje urbano barcelonés ${ }^{22}$.

La iglesia de Santa Maria del Pi resulta la más solicitada por la ciudadanía, lo cual no debe extrañar puesto que se trata de la parroquia de uno de los quarters más populosos y activos de la Barcelona bajomedieval. Los testadores que desean ser enterrados allí componen un grupo heterogéneo, con un predominio abrumador de menestrales (sastres, traginers, lapicidas, fusters, espasers, ferrers, etc.) junto a algún representante de la Iglesia ${ }^{23}$ y de la casa real ${ }^{24}$. Es notable, sin embargo, la ausencia de miembros de las profesiones liberales (notarios, juristas, abogados, apotecaris, médicos, etc.) y de aquellos que se dedican al comercio o pertenecen a la banca y al mundo de los negocios en general ${ }^{25}$.

La Catedral barcelonesa ocupa el segundo lugar en cuanto al número de solicitudes. Casi un $13 \%$ de los testadores estudiados cursa instrucciones a los albaceas para que se ocupen de enterrar sus restos en el cementerio de la primera iglesia de la ciudad, entonces en obras. En este grupo, más homogéneo que el

de edad, los únicos habidos en sus cuatro matrimonios [Ver J.E. MARTínEZ FERRANDO, Jaimo Il de Aragón. Su vida familiar, I, Barcelona, CSIC, 1948, p. 33].

20 Una parte cubrirá los gastos del sepelio y el resto servirá para atender cualquier reclamación o saldar pequeñas donaciones a instituciones religiosas o mendicantes. La fórmula empleada es invariablemente la misma: Accipio axtem de bonis meis pro anima mea ot sepultura et pro loxiis mois infrascriptis faciondis... y a continuación se detalla la relación de legados y disposiciones.

21 Ver infra, Cuadro 2: Elección de sepultura.

22 La expansión del cristianismo supone el fin de la antigua práctica romana -y también germánica- de inhumar a los muertos en el campo, lejos de las murallas de la ciudad. Como dice Salvador Claramunt: «Lo primero que destaca en el paisaje de cualquier centro urbano hasta el siglo XIX son los cementerios, situados junto a la iglesia parroquial, [S. CLARAMUNT, La muorte en la Bdad Modia, p. 205].

23 El presbítero Guillem Haubert destina 5 ss. a la iglesia y 6 ds. a cada uno de sus altares, a cargo de la cantidad global de 200 ss. que deja pro anima et sopaltura [ACB, N, BV, MT, f. 76r-v].

24 Arnau Gassull, hijo de un porter de Jaume II, expresa su voluntad de ser enterrado junto a su madre y deja 10 ss. para la sepultura y otros 20 para las obras de la iglesia [Ibidem, ff. 168v-169v].

2s Entre todos ellos no hay un solo mercader o cambista, únicamente aparece un draper [lbidem, ff. 135v-136v] y Clara, la mujer de un conocido notario [lbidem, ff. 77r- 81v]. 


\begin{tabular}{|c|c|c|c|c|c|}
\hline & Hombres & Mujeres & \& Hombres & \& Mujeres & i Total \\
\hline sta. $M$ del $P i$ & 16 & 15 & $10 \cdot 60$ & 10 & $20 \cdot 66$ \\
\hline Catedral & 12 & 7 & 8 & $4 \cdot 66$ & $12 \cdot 66$ \\
\hline Framenors & 7 & 7 & $4 \cdot 66$ & $4 \cdot 66$ & $9 \cdot 32$ \\
\hline Sant Pere & 5 & 4 & $3 \cdot 33$ & $2 \cdot 66$ & $5 \cdot 99$ \\
\hline Sta. Ma del Mar & 5 & 3 & $3 \cdot 33$ & 2 & $5 \cdot 33$ \\
\hline Sant Jaume & 5 & 3 & $3 \cdot 33$ & 2 & $5 \cdot 33$ \\
\hline Predicadors & 2 & 4 & $1 \cdot 33$ & $2 \cdot 66$ & $3 \cdot 99$ \\
\hline Sant Just & 2 & 3 & $1 \cdot 33$ & 2 & $3 \cdot 33$ \\
\hline sta. M Carme & 1 & 2 & 0.66 & $1 \cdot 33$ & $1 \cdot 99$ \\
\hline Jonqueres & 1 & 2 & 0.66 & $1 \cdot 33$ & $1 \cdot 99$ \\
\hline Sta. Anna & -- & 3 & -- & 2 & $1 \cdot 99$ \\
\hline Sant Miquel & 2 & 1 & $1 \cdot 33$ & 0.66 & $1 \cdot 99$ \\
\hline
\end{tabular}

\section{Cuadro 2: Elección de sepultura}

anterior, concurre el denominador común de la riqueza y del poder político o religioso, pues en él se encuentran personajes tan influyentes como Brunissenda de Cervelló y su hermano Hug de Cardona ${ }^{26}$, además de mercaderes ultramarinos, jurisperitos, funcionarios municipales e individuos de las grandes familias de ciutadans honrats (Gruny, Llull, Palau, Boquer, Sabastida, etc.) ${ }^{27}$. La condición de todos ellos guarda una estrecha relación con el papel social que desempeña en estos

26 Brunissenda de Cervelló nos ha dejado su testamento y dos codicilos, llenos de interesantísima información inédita [lbidem, ff. 29v-32r]. Estuvo casada con Guerau de Cervello, hombre de confianza del rey, y era hermana de Hug de Cardona, arcediano de Barcelona, y del fallecido Ramon Folch, vizconde de Cardona. Fue una de las damas más influyentes de Barcelona y sabemos que residía en un palacio situado en la plaza de Santa Anna, donde en 1313 se alojaron los embajadores austríacos que acudieron con motivo del matrimonio de la infanta Isabel y el duque Federico. El estado de conservación del Palau Reial Major dejaba en estos momentos mucho que desear y Jaume II decidió buscarles una residencia más acorde con su condición [ACA, C, reg. 241, f. 52r].

27 Jaume Gruny, por ejemplo, lega cantidades importantes de dinero y demuestra estar en posesión de una gran fortuna. Para liquidar las deudas que en vida contrajeron sus difuntos padre y hermano Pere, pone a disposición de sus albaceas las rentas que percibe por su casa fortificada y sus molinos de Santa Coloma, que ascienden a 20.000 ss. [ACB, N, BT, MT, ff. 121r-123v]. 
momentos la Catedral, pero sus muros no están cerrados al grueso de los ciudadanos pertenecientes a sectores menos favorecidos de la población-como es el caso, por ejemplo, de un marinero, un sabater, un carretero o un corredor-. Los legados que estas gentes establecen para la sepultura y ritual funerario superan ostensiblemente aquéllos destinados a la iglesia de Santa Maria del Pi.

Los datos consultados ponen de relieve, asimismo, el interés de los testadores por las casas que los franciscanos y dominicos poseen en la ciudad, así como por los distintos monasterios (Sant Pere de les Puelles, Santa Anna y Santa Maria de Jonqueres) y parroquias repartidas por el burgo y el raval (Santa Maria del Mar, Sant Jaume, Sant Just o Sant Miquel). Parece, sin embargo, que determinadas instituciones religiosas no gozaban del favor de los fieles, lo cual se refleja en la poca entidad de los legados que reciben, como es el caso de los carmelitas o del convento femenino de Santa Maria de Jonqueres ${ }^{28}$. Es posible que la escasa popularidad de unos y otras obedezca al corto período de tiempo que llevan instalados en Barcelona ${ }^{29}$.

Los Hermanos Predicadores tampoco se benefician de la generosidad de los ciudadanos a la hora de disponer fondos pro anima et sepultura, pero este olvido se ve ampliamente compensado por multitud de donaciones de otra índole (provisión de mesa y despensa de los frares, celebración de misas y aniversarios, vestidos y ropas de cama para los necesitados de la parroquia, etc.) y, sobre todo, por legados en metálico. El porcentaje de testadores que muestran su preferencia por el cementerio barcelonés de los dominicos es muy reducido aunque, sin embargo, muchos de ellos les recuerdan a la hora de repartir su fortuna y esta conducta es fiel reflejo de la rapidez con que esta comunidad supo conectar con los diversos estamentos sociolaborales. La Orden se instaló en la Ciudad Condal en 1219 y las obras de construcción de su casa finalizaron en 1268 , consiguiendo desde los primeros días de apostolado una gran popularidad entre las gentes. Algunos de sus miembros se introdujeron fácilmente en los ambientes de la adinerada burguesía mercantil, actuando en su seno como confesores y ejerciendo después el papel de albaceas y personas de confianza, de modo que consiguieron canalizar en su propio beneficio un volumen importante de los capitales circulantes ${ }^{30}$. Con esta succión de fondos privados, procedentes en su mayoría de la caridad de los ciudadanos, no tardaron en iniciar una serie de actividades financieras e inversoras -dirigidas mayoritariamente a la

28 A lo largo de casi cuarenta años Santa Maria del Carme recibe tan sólo la cantidad de 16 ss. pro anima et sopultura entregados por el fuster Pere Torrent [lbidem, ff. 19v- 20r] y por dos barcelonesas de la menestralía [lbidem, ff. 1 r y $36 v-37 r$. Apenas el $2 \%$ de los testadores del Manwal desea ser enterrado en su cementerio. En Jonqueres no es mayor la cifra (15 ss.) y se mantienen los mismos porcentajes. Ambas instituciones son elegidas preferentemente por el elemento femenino de la población.

29 Los carmelitas se establecieron en la Ciudad Condal a mediados del siglo XIII junto a los Hermanos de la Penitencia o frares del sac, mientras que las monjas benedictinas fundaron inicialmente su casa en la parroquia de Sant Vicenç de Jonqueres (entre Sabadell y Terrassa) en torno al año 1214, pasando a Sabadell en 1237 y desde allí por motivos de seguridad a Barcelona, donde se acogen a la regla de la Orden de Uclés. El primer cenobio fundado intramuros data de 1293 y el primer testamento del Manual cuyo titular desea ser enterrado en Jonqueres está fechado en 1309 [lbidem, ff. lv- 2v]; es decir, tan sólo tres lustros desde su aparición en la vida ciudadana.

30 Los ejemplos acerca de la conexión entre los dominicos y las clases altas (nobleza, hombres de negocios, ciutadans bonrats, profesionales liberales, etc.) abundan en las fuentes consultadas. Muy representativo es, por 
compraventa de censos- y empezaron a gestionar ellos mismos sus negocios, obteniendo así buenos dividendos y olvidando en parte la antigua norma fundacional de la Orden ${ }^{31}$.

Casi un $10 \%$ de los testadores consultados expresa la voluntad de ser enterrado, por otra parte, en el convento de los framenors, quienes gozan de una popularidad semejante a la de los dominicos. Sabemos que esta Orden Mendicante construyó su edificio barcelonés (situado fuera de las antiguas murallas, más allá del Portal de Regomir) entre 1236 y 1253, gracias a la aportación económica de los ciudadanos y muy pronto se difundió la costumbre de solicitar el hábito de San Francisco para amortajar el cadáver, correspondiendo a este honor mediante el establecimiento de un legado material ${ }^{32}$. Por todo ello el potencial de estos hermanos de la pobreza y la vida contemplativa debió ser cuantioso, viéndose incrementado en 1287 por la donación que realizó a su favor Alfonso el Liberal, quien decidió cederles las rentas de los molinos reales de la ciudad, valoradas en unos 6.000 ss. anuales.

Las iglesias parroquiales, como Sant Just o Sant Miquel, no destacan por el número de aquellos que desean ser inhumados en sus cementerios (entre ambas representan tan sólo el 5'32\% del total de testadores computados, cifra similar a la que arroja la parroquia de Sant Jaume). Pero estos bajos porcentajes son superados, incluso, por instituciones como Santa Eulàlia del Camp, donde solicita su tumba un único ciudadano $^{33}$. Quizás la explicación a este desinterés de la población hay que

ejemplo, el caso de Joan Llotger, confesor de una serie de ciudadanos pertenecientes a los clanes del poder y del dinero (Sentmenat, Llull, Descortell, Gruny, etc.). Su actuación se extiende a lo largo de poco más de una década (1321-1333) y todos estos testadores le recuerdan a la hora de disponer de sus bienes, dejándole legados que oscilan entre los 20 ss. de Francesca Romeu, la viuda de Guillem Llull [16idem, ff. 116r-118r], y los 100 ss. de Bernat Soler, procurador del economato de la casa de Sant Pere de les Puelles [1bidem, ff. 72v-75v]. La conexión de este frare predicador con la oligarquía urbana no es de extrañar ya que desempeñó, a lo largo de su vida, un papel ciertamente importante. En 1327, ante la inminente muerte de Jaume II, formó parte de la comisión delegada para atender las demandas de cuantos se sentían agraviados por la Corona. Junto a él se encontraban, en dicha comisión, los más prestigiosos juristas del momento y, entre ellos, su compañero de Orden Bernat de Puigcercós, autor de un interesante quodlibet sobre censales y violarios desde el punto de vista moral y ético [Ver J. HERNANDO, El problema del crèdit i la moral a Catalunya (segle XIV), «Acta/Mediaevaliaw, Annex 1, Barcelona, 1983, pp. 113-136].

31 Según algunos autores, la casa de los dominicos en Barcelona recuerda más un banco que un lugar de culto [Ver C. BATLLE-M. CASES, La caritat privada $i$ les institucions bendfiques de Barcelona (segle XIII), «La pobreza y la asistencia a los pobres en la Cataluña medievaln, I, Barcelona, CSIC, 1980, pp. 117-190].

32 Las fuentes documentan la figura de algunos framenors ejerciendo sus actividades entre la población, como Pere Forn, confesor de Sibil.la de Lliçà, viuda del miles Ramon de Vilanova, que recibe un legado de 30 ss. y consigue además que la causante legue $100 \mathrm{ss}$. al convento barcelonés de la Orden para celebrar misas y otros 50 pro pitancia [ACB, N, BV, MT, ff. 85v-87r]; Ponç Carbonell, confesor, junto al ya citado Joan de Llotger, del jurisperito Berenguer Descortell, recibe 30 ss. para él y 60 para el convento [Ibidem, ff. 53r-56r]; Francesc Clarà, testigo del mercader Guillem Sitges [16idem, ff. 46r-49v]; Francesc Esteve, testigo del también mercader ultramarino y armador Francesc Sacosta [lbidem, ff. 110r-111v]; Ramon Ferrer y Joan Desquer, que reciben sendos legados de 50 y 20 ss. de Clara de Santquirçe, mujer del notario Francesc Refechs [lbidom, ff. 77r-81v]; o Pere Jofret, que se ve favorecido con un legado de 50 ss. del miles Roger de Castellcir [lbidem, ff. 24v-27 r]. En ocasiones, los franciscanos proceden del seno de las familias poderosas de Barcelona y por ello su conexión con la oligarquía es más evidente. Un ejemplo digno de mención es Guillem Sala, hijo del mercader del mismo nombre y cuñado del rico cambista Jaume Abril [lbidem, ff. 125r-129r], a quien en 1334 vemos convertido en rector de la iglesia de Sant Miquel [16idem, ff. 155v-156v] y ejerciendo como albacea, testigo, confesor o legatario de sus conciudadanos mejor situados socialmente.

33 Se trata precisamente de un presbitero, Ferrer Huguet, que detenta un beneficio en la iglesia del propio monasterio y lega todos sus bienes a la comunidad [Ibidem, ff. $141 \mathrm{v}-142 \mathrm{r}$ ]. 
buscarla, en el caso de esta comunidad de agustinos, en la mala fama adquirida a causa de la deficiente gestión llevada a cabo por su administrador Bartomeu Descoll, quien en torno al año 1300 malversó los fondos y enajenó los bienes del hospital situado en el monasterio, motivando el arbitraje del propio obispo Ponç de Gual$\mathrm{ba}^{34}$.

Conductas deshonestas como la del administrador de Santa Eulàlia del Camp debían producirse con cierta frecuencia, si tenemos en cuenta que grandes sumas de dinero se concentraban en manos de un solo individuo. Es obvio que algunos administradores y ecónomos de instituciones religiosas y hospitalarias, encargados de manejar fondos cuantiosos, se aprovecharían de su ventajosa situación desviando bienes en su propio beneficio ".

En definitiva, las entidades religiosas de Barcelona reciben el dinero de los ciudadanos piadosos por muy diversas razones, entre las cuales destaca el derecho a recibir sepultura. El análisis de estos legados ratione sepulture evidencia la cuantía de los ingresos obtenidos por la Catedral frente a otras iglesias y parroquias y marca, además, la diferenciación social de los futuros inquilinos de su cementerio ${ }^{36}$. Pero el lugar elegido no corresponde necesariamente a la parroquia del testador, es decir, a la iglesia donde recibió el bautismo. En muchos casos los barceloneses optan por el camposanto de conventos y monasterios de su devoción y proceden, casi siempre, a ordenar legados en metálico a las dos instituciones: la sepulcral y la parroquial.

$\mathrm{Y}$, finalmente, es preciso destacar que no todos los ciudadanos se muestran unánimemente partidarios de reposar en los cementerios urbanos. Un buen número de ellos se decide por disponer su sepultura en las iglesias y monasterios del territorio jurisdiccional o en zonas más o menos alejadas, aludiendo así a su lugar de origen. Esta elección es comprensible en una ciudad como Barcelona, dotada de un fuerte componente de población de aluvión y que actúa como foco de atracción respecto al Principado. En efecto, la inmigración que se produce en estos momentos hay que entenderla como una consecuencia lógica de la peculiar situación que vive la Ciudad Condal a principios del siglo XIV. El despegue generalizado de la economía, el desarrollo del comercio, el volumen alcanzado por el tráfico de mercancías, la apertura de nuevas rutas marítimas y terrestres o la adopción de sofisticadas técnicas de contratación y flete van a potenciar el crecimiento de una manufactura propia y a provocar la llegada de gentes que serán absorbidas por los sectores productivos en

34 El rector Descoll fue acusado de cargos tan curiosos como llevar armas públicamente, tocar instrumentos musicales o jugar a los dados, además de asuntos más serios como el hecho de deshonrar a una criatura de 12 años de edad y retenerla en el edificio hospitalario [Ver C. BATLLE-M. CASES, La caritat privada, I, p. 142].

39 El año 1321 formaliza su testamento Bernat Soler y declara que tiempo atrás ejerció el cargo de procurador del economato del monasterio de Sant Pere. Ahora, enfrentado a la muerte, confiesa haber cometido algunas irregularidades y se muestra arrepentido, solicitando el perdón de la abadesa y un recuerdo en sus oraciones. El delito de Bernat fue poner en manos de los usureros judíos ciertas sumas del dinero a su cargo, así como recibir intereses generados por el capital de la comunidad sin conocimiento de sus administradas. Su conciencia le lleva a legar 1.000 ss. al monasterio, otros 100 a la abadesa y 12 ds. a cada novicia para enmendar su pasada acción [ACB, N, BV, MT, ff. $72 v-75 v]$.

36 Entre 1300 y 1339 la Catedral recibe 16 legados por este concepto, que ascienden a $20 \mathrm{lbs}$. y 13 ss., mientras que Santa Maria del Pi recibe el doble (30 legados) e ingresa solamente un tercio (6 lbs. y 14 ss.). Esta diferencia realza el carácter popular de la parroquia del quarter del Pi y el cariz selectivo de la Sede barcelonesa. $A$ destacar asimismo los 5 legados destinados a la casa de los framonors, que suman un total de 15 lbs. y 15 ss. 
auge. Por otra parte, el papel político y diplomático desempeñado por Barcelona en el contexto del mundo mediterráneo, junto al hecho de albergar a la familia real -lo cual le confiere cierto carácter de capital del reino- atrae a la baja nobleza del territorio, deseosa de residir cerca del centro del poder político y obtener así beneficios y prebendas ${ }^{37}$.

Estos datos vienen a demostrar que los barceloneses ejercen sin paliativos su derecho a la libre elección de sepultura, disponiendo a voluntad el futuro destino de sus restos mortales. Las restricciones impuestas por la Iglesia en este sentido debieron ser mínimas y estarían condicionadas tan sólo por motivos de infraestructura (obras en el templo o cementerio, falta de espacio, etc.) o por razones de índole moral (impenitentes reconocidos, ejecutados por la justicia, suicidas, criminales convictos, etc.) ${ }^{38}$.

La proliferación de cementerios en Barcelona, dentro y fuera del primer circuito de murallas, posibilita la elección de la ciudadanía y confiere al paisaje urbano un aspecto muy peculiar, con todo el aparato de losas, cruces y demás símbolos de la piedad -o del poder económico- de sus propietarios. Este paisaje no va a sufrir cambios profundos hasta época muy tardía y, más concretamente, hasta el último cuarto del siglo XVIII, momento en que Carlos III dicta la abolición de los cementerios de las iglesias parroquiales y se decide su transformación en plazas públicas. Hacia 1775 algunas necrópolis de superficie ya habían desaparecido y las restantes permanecían, pero su utilización estaba supeditada a una compleja normativa tendente a su definitiva abolición. De cualquier modo, la prohibición del monarca de la casa de Borbón supone un freno a la continuidad de los cementerios parroquiales y marca el cambio de mentalidad hacia su concentración en puntos más alejados del casco urbano designados al efecto ${ }^{39}$.

37 El porcentaje que ofrecen los testamentos consultados es significativo pues el número de titulares que desean ser enterrados lejos de la ciudad (25\%) no es nada despreciable frente a aquéllos que optan por los cementerios urbanos (75\%). Entre los primeros abundan, como es lógico, los miembros de la pequeña nobleza de armas (milites) como Roger de Castellcir [ACB, N, BV, MT, ff. 24v-27r] o Guillem de Viladecavalls [Ibidem, ff. 64v-67r], cuyos apellidos indican bien a las claras su lugar de origen. Junto a ellos se sitúa toda una serie de menestrales integrados en diversos oficios, además de profesionales liberales y hombres de negocios, cuya procedencia es heterogénea: Sant Cugat, Rubí, Martorell, Molins de Rei, Olesa de Montserrat, Cervelló, Vic, Manresa, Perpinyà, Cervera, etc. Todos ellos ordenan ser enterrados en las parroquias de sus villas y ciudades natales: Santa Maria de Martorell, Sant Pere Octaviano, Sant Vicenş de Cervelló, Sant Bartomeu d'Olorde, Santa Eulàlia de Berga, Sant Pau d'Ordal, etc.; y también en los monasterios o conventos de las distintas Órdenes religiosas y militares: el Hospital de Sant Joan de Jerusalem (Cervera), los Predicadores (Manresa o Vilafranca del Penedès), Sant Cugat del Vallès, Sant Miquel del Fai, etc.

38 En un solo caso el testador parece tener dudas acerca de su derecho a ser inhumado donde solicita. Se trata de una ciudadana que pide ser enterrada en la parroquia de Santa Maria del Pi si ibi non sit interdictum [lbidem, $\mathrm{f}$. $13 \mathrm{r}-\mathrm{v}$.

39 En el momento de la normativa borbónica de 1775 ya habian desaparecido los cementerios de las parroquias de Sant Jaume y Sant Pau, de los hospitales de Colom, Marcús y Sant Joan, del exterior de la Catedral y otros más. Existían aún los de Sant Miquel, Santa Maria del Pi, Sant Pere de les Puelles, Sant Just, etc., mientras que algunos, situados en el interior de la fábrica religiosa (en el subsuelo de la nave o en el claustro), funcionaron hasta bien entrado el siglo XIX, como los de la Catedral, Sant Pau del Camp y Framenors. En 1801 se prohibe cualquier tipo de obras en el cementerio de Santa Maria del Mar y al año siguiente, el Ayuntamiento, pretextando que debe ser acondicionado para la visita del rey, emprende su rebaje y, finalmente, en 1806 se decide su conversión en plaza, que aún existe en la actualidad [Ver F. CARRERAS CANDI, La cistat de Bancelona, «Geografia General de Catalunyaw, I, Barcelona, Impr. A. Marin, s/f, pp. 825-828]. 


\section{I.3 Liturgia y ritos funerarios}

La idea de la muerte provoca en la población barcelonesa una preocupación que se traduce en el detalle minucioso de toda la ceremonia a seguir por los clérigos y oficiantes encargados de disponer el entierro y celebrar los funerales. Básicamente las órdenes dictadas al respecto por los testadores del primer tercio del siglo XIV van dirigidas a dos situaciones bien diferenciadas ya que, por una parte, se refieren al mismo día del fallecimiento y, por la otra, a la manera en que su cadáver recibirá cristiana sepultura. Para que estas últimas voluntades se cumplan debidamente se reserva siempre una parte proporcional de fondos, asignada en general a los albaceas pero también a clérigos y demás personas que gozan de la confianza del causante, los cuales actuarán en consecuencia y dispondrán de dicha suma prout eis melius visum fuerit.

Los aspectos concernientes al día de la muerte consisten preferentemente en la compra de cirios, velas o hachones y su colocación junto al cadáver ${ }^{40}$, aunque a menudo se expresan deseos específicos como vestir un hábito determinado por el que se siente especial devoción ${ }^{41}$. Este detalle de la mortaja se refiere indistintamente al día del óbito (die quam obiero) o al día del sepelio (die quam corpus meum tradatur ecclesiasticam sepulturam; die ubi corpus meum sepultum fuerit, etc.). Las órdenes respecto al entierro, por su parte, giran en torno a las misas de difuntos, el número de presbíteros celebrantes, la asignación a percibir por cada uno de ellos, las cruces que acompañarán el cadáver hasta el cementerio elegido, el banquete funerario e incluso la asistencia económica a los pobres que ese día se congreguen junto a la tumba.

Una costumbre muy arraigada, y que forma parte del ritual funerario, es aquélla que consiste en la dedicación de lámparas votivas a un altar de la devoción del causante. Estas lámparas se encenderán el día de la muerte y así los fieles recordarán al difunto en sus oraciones ${ }^{42}$. En cuanto a los detalles puramente

40 Son innumerables los ejemplos de esta práctica funeraria utilizada por los habitantes de Barcelona. Una muestra la encontramos ya en las primeras páginas del Manual, cuando el picapedrer Pere Dosrius ordena a sus albaceas que compren 4 cirios de 6 lbs. de peso [ $A C B, N, B V, M T$, ff. 3r-4r]. A partir de ahí la información es exhaustiva: Elisenda, casada con el maestro de gramática Esteve de Montnegre, pide 6 cirios [lbidem, f. 21v]; Sibil.la de Vilanova desea 20 hachones «de buena ceraw [lbidem, ff. 85v-87r]; los mercaderes Mateu Oliver [lbidem, ff. 169v-170v] y Guillem Carbonell [lbidem, f. 151r], igual que su conciudadano Pere Dosrius; y finalmente una menestral oriunda de Terrassa aprovecha la ocasión para donar grandes cantidades de cera a diversos monasterios de la diócesis [lbidem, ff. 56v-58v].

41 La preocupación por la mortaja se refleja en multitud de ciudadanos que solicitan ser vestidos con hábitos o bien con finas telas de lino blanco o algodón. Es el caso, por ejemplo, de Guillema Bellestar, que ruega a la abadesa de Sant Pere que le conceda a título póstumo el hábito de la Orden [16idem, ff. 2v-3r]; la citada Sibil.la de Vilanova deja 35 lbs. (cantidad muy considerable) para que la amortajen con un lienzo de lino bordado en oro [lbidem, ff. 85v-87r]; Pere Sitjar, funcionario de la Hacienda real [lbidem, f. 32r-v], Clara, la mujer del notario Francesc Refechs [Ibidem, ff. 77r-81v] y una viuda llamada Sança [lbidem, f. 151v], se deciden también por la mortaja de lino; Elisenda de Mora, rica propietaria de bonors [1bidem, ff. 178v-180v], y Saurina, hija del difunto miles Albert de Mediona [lbidem, ff. 193r-194v], quieren vestir el hábito de San Francisco de Asís, lo mismo que los mercaderes Guillem Sala [lbidem, ff. 125r-129r] y Bernat Carnicer [lbidem, ff. 123v-125r], mientras que Celia, la viuda del procurador Bernat Soler [lbidem, ff. 72v-75r], confiesa su devoción por San Benito [lbidem, ff. 183v-186r].

42 Así actúan una serie de ciudadanos de muy diversa condición, unidos entre sí por el carácter homogéneo de sus últimas voluntades. El temor a la muerte y, sobre todo, a la condenación eterna, va a actuar como elemento estabilizador post mortem, de modo que el comportamiento de ricos y pobres, menestrales y cavallers, nobles y 
necrológicos, como el lavado del cadáver o la identidad de las personas encargadas de amortajarlo y vestirlo, se produce un silencio documental muy acusado. Los testamentos barceloneses no aportan un sólo detalle al respecto, lo cual hasta cierto punto resulta comprensible ya que es difícil imaginar a nadie, bajo ninguna circunstancia ni momento histórico, dictando las órdenes oportunas para el adecentamiento de su propio cuerpo ${ }^{43}$.

Las disposiciones para el día del sepelio que gozan de mayor predicamento entre los barceloneses se refieren, en general, a las cruces que acompañarán el cadáver al cementerio y a las misas de difuntos. Algunas de estas costumbres tuvieron un gran arraigo entre la población bajomedieval y han sido suficientemente estudiadas por la historiografía actual. Los testamentos constituyen, una vez más, una fuente de información muy valiosa y proporcionan gran cantidad de datos acerca de estas prácticas funerarias. En general, ambas costumbres pertenecen al campo de la historia colectiva de la Ciudad Condal ya que son practicadas sin distinción por todo tipo de habitantes, al margen de consideraciones sociales o laborales. Tanto los representantes de la menestralía como los miembros de la nobleza y de la Iglesia, sin olvidar a todos cuantos ejercen actividades englobadas en el sector terciario (comercio, profesiones liberales, alimentación, transporte, servicios, etc.), se muestran partidarios de esta liturgia post mortem.

Es habitual, en este sentido, que el día del entierro los clérigos designados al efecto acompañen con las cruces alzadas los despojos mortales del causante hasta el cementerio, transportando su carga a lomos de caballería o sobre las espaldas de familiares y amigos ${ }^{44}$. Como es natural, tales prestaciones se ven recompensadas mediante un legado más o menos generoso destinado a cubrir los servicios realizados. Muchos testadores, procedentes de los más variados sectores sociolaborales, utilizan este mecanismo para suavizar el tránsito a la otra vida, pero suele darse entre los

mercaderes, etc. responde a los mismos patrones mentales [Ver J.R. JULIÁ VIÑAMATA, La menestralía barcelonesa del primer tercio del siglo XIV a través de un manual notarial de testamentos, "Actes del II Congrés d'Història del Pla de Barcelonan, I, Barcelona, IMH, 1989, pp. 277-292]. Algunos ejemplos de esta costumbre aparecen en los testamentos del citado señor de Castellcir, que encarga una lámpara para que arda de die noctique en el altar de Sanţa Maria de Savall [ACB, N, BV, MT, ff. 24v-27r]; de Guillem Arenys, de la parroquia de Sant Esteve de Parets, que encarga una lámpara para el altar de Santa Cília [lbidem, ff. 93v-95r]; o del jurisperito Berenguer Descortell que se decide, en cambio, por un cáliz de oro para el alcar de Sant Pau [1bidem, ff. 53r-56r].

43 La arqueología puede servir de gran ayuda en este campo, al igual que el estudio de la iconografía. En la Castilla bajomedieval, por ejemplo, perdura la costumbre de lavar el cadáver de los difuntos, tal como puede apreciarse en las representaciones del monasterio cisterciense de Santa María de Huerta (Soria) [Ver M. RIU, Alguns costums funeraris, p. 31].

44 Esta es la liturgia que practica, por ejemplo, Sibil.la de Vilanova cuando ordena que el día de su funeral asistan tantos presbíteros de las iglesias del Baix Llobregat como sea posible, procediendo todos ellos a celebrar misas por su alma. Los albaceas aprovecharán la ocasión, siempre según las instrucciones de la testadora, para entregar 12 ds. a cada uno de los que lleven la cruz de Sant Boi hasta su tumba [ACB, N, BV, MT, ff. 85v-87r]. En 1320 es Pere Carbó, recaudador de fondos al servicio del rey, quien desea que le acompañen las cruces de los hospitales de pobres y enfermos [ 1 bidem, ff. 43r-44v]; un año más tarde el ecónomo de Sant Pere, Bernat Soler, en un alarde de liberalidad, lega 2 ss. a cada una de las distintas iglesias parroquiales de Barcelona, con la condición de que acudan los frares y clérigos con sus correspondientes cruces alzadas [Ibidem, ff. 72v-75r]; Guillem Carbonell, en cambio, no especifica el número ni la condición, pero lega 2 ss. a cada iglesia que envíe representantes con sus cruces [Ibidem, ff. 151r-152v]; y de la misma forma actúa Brunissenda, viuda de Guillem de Vilaseca, en 1334 [Ibidem, f. 150r-v]. 
burgueses adinerados -y mestres de los oficios- con mayor asiduidad que en el seno de la nobleza o entre los propios clérigos.

Respecto a las misas post mortem, ordenadas por los propios ciudadanos con efectos purificadores, nos encontramos no tanto ante un mero elemento ceremonial sino más bien ante un sencillo ritual que tiende a garantizar los rezos y el perdón de los asistentes. Todo ello persigue un objetivo muy específico: la salvación del alma y la consiguiente entrada en el Paraíso, de modo que se aleje definitivamente la tenebrosa posibilidad del infierno.

La intención del testador es, pues, fácilmente ejecutable por parte de albaceas y herederos. Consiste únicamente en seguir las instrucciones referentes al número y categoría de los oficiantes, satisfaciendo a cada uno de ellos la suma que le ha sido asignada en la escritura. Por tal razón estas disposiciones mortis causa son muy similares entre sí y difieren tan sólo en sus aspectos formales, adecuados a la condición social y riqueza personal de su titular ${ }^{45}$. Pero los fondos que reciben las comunidades religiosas de la ciudad, a cambio de la ayuda espiritual prestada, son cuantiosos. En general, los mayores ingresos corresponden al capítulo de misas y oraciones pro anima y pocos conventos, monasterios o casas de las Órdenes que ejercen su apostolado en Barcelona dejan de percibir dividendos por estos moti$\operatorname{vos}^{46}$.

Esta costumbre no es ejercida de forma exclusiva por los miembros de la oligarquía urbana, ya que un estudio comparativo de buen número de testamentos pone de relieve que la ciudadanía en general cree firmemente en la utilidad de las misas y el encargo de oraciones, aunque la diferencia entre unos y otros estriba en las dificultades económicas de algunos sectores sociales, lo cual les impide financiar el alto coste de este peculiar remedio para la salud del alma ${ }^{47}$.

En definitiva, este comportamiento ritual y piadoso es patrimonio de los barceloneses del primer tercio del siglo XIV, quienes han heredado ciertos hábitos de sus mayores pero también han aportado sus propias innovaciones. El contenido de

45 Los barceloneses acomodados suelen ordenar que la misa sea celebrada por dos o tres oficiantes, recibiendo cada uno por sus servicios un legado que gira en torno a 6 u $8 d s$; pero a menudo este número se amplía considerablemente, como es el caso de la viuda del sastre Guillem Ram que dispone la asistencia de 50 presbíteros [Ibidem, ff. 60v-64v]. En ocasiones, el testador no detalla el número de celebrantes y se preocupa en cambio por la frecuencia de las misas: el mercader Bernat Cervera, por ejemplo, quiere que se oficien en los framenors durante los cuatro días siguientes a su muerte [1bidem, ff. 97r-99r], mientras que Pere Carbó encarga 300 misas a los dominicos [lbidem, ff. 43r-44v].

46 Resulea innecesario enumerar todos y cada uno de estos legados, muy parecidos entre sí, pero sirva a modo de ejemplo el caso de Hug de Cardona, quien cede 50 ss. a la casa de Santa María de Nazaret, al prior del Císter, al monasterio de Jonqueres y al de Valldonzella, rogando a los frares que eleven sus oraciones por el bien de su alma [Ibidem, ff. 103r-106r]. Su hermana Brunissenda de Cervelló entrega idéntica cantidad a una serie de conventos (franciscanos, dominicos, carmelitas, mercedarios y agustinos) y monasterios (Sant Pere, Jonqueres y Valldonzella), dictando las órdenes oportunas en cuanto a su ejecución [Ibidem, ff. 29v-31r].

17 Esta conducta priva entre los grupos sociales dominantes a nivel crematístico, pero en el campo de las mentalidades es común a todos los ciudadanos. La diferencia entre Hug de Cardona o su hermana Brunissenda de Cervelló [Ver supra, nota 46], por ejemplo, y el bataner de fustanys Bernat Rubí [lbidem, ff. 4v-5v] radica en que los primeros se permiten establecer onerosos legados, mientras que el segundo debe conformarse con el sobrante de la cantidad que destina para la sepultura, los legados pios y las deudas. Son muy numerosos los testadores menestrales y trabajadores del sector secundario, en general, que se pronuncian en este sentido, rogando que una vez liquidadas todas las cargas y legados se emplee el resto, en caso de que se produzca un excedente, en celebrar misas. 
muchos testamentos recuerda, sin duda, el mecanismo de las antiguas donationes pro anima $^{48} \mathrm{y}$, dado el número de legados píos que establecen algunos ciudadanos, el papel desempeñado por los albaceas -ejecutores de las últimas voluntades del causante-se asemeja notablemente al de los antiguos elemosinarii altomedievales ${ }^{49}$.

\section{I.3.1 Los banquetes de difuntos}

La asignación de ciertas cantidades de dinero, por parte de los testadores barceloneses, destinadas a proveer la mesa de clérigos y menesterosos el día del entierro constituye otra de las manifestaciones más evidentes de la mentalidad colectiva de la ciudadanía de la época. En realidad se trata de una costumbre tradicional en Cataluña, documentada ya en el siglo XII, que suponía la presencia de familiares y demás acompañantes del cadáver en la vivienda del difunto, una vez realizado el sepelio y la misa funeral, donde eran invitados a participar en un banquete. Sabemos, por la iconografía, que en la Barcelona trecentista la comida consistía básicamente en pan, vino y algo de carne, pero carecemos de más datos.

Este ágape ritual ha subsistido hasta nuestros días en algunas comarcas catalanas (Empordà, Solsonès o Berguedà, por ejemplo) ${ }^{\text {so }}$, aunque los banquetes de principios del siglo XIV no iban dirigidos al grupo reducido de asistentes al sepelio

48 Las donationes pro anima aparecen a lo largo de los siglos VII-VIII en aquellas zonas donde, de forma progresiva, decaen las instituciones romanas. El testamento se aleja de las formas tradicionales del Derecho Romano y se empieza a imponer este tipo de donaciones, paradójicamente, en una de las provincias más romanizadas de Occidente, la Galia. De este modo, en Borgoña o el Delfinado se suple la forma testamentaria tradicional por la donación pro anima, consistente en una declaración obligatoria de últimas voluntades que contempla los legados píos, mientras que en Septimania se mantiene en todo su vigor el testamentum romano, lo cual llevó a Jean Bastier a afirmar que rel Midi de la vieja Galia aparece como la reserva de las ideas romanas» [J. BASTIER, Le testament en Catalogne du IXe au XIle siècle: une survivance wisigothique, «Revue Historique de Droit Français et Étranger", 51 (Paris, 1973), p. 381]. En la Europa meridional destaca, por otra parte, la pervivencia del testamento como forma generalizada de disposición de bienes en la sucesión voluntaria, en contraposición a los reinos bárbaros no mediterráneos -donde el sistema de transmisión pro anima privará sobre la sucesión testada-. Este aspecto ha sido puesto de manifiesto por Antonio Udina, quien destaca la vigencia del testamento en Italia, Septimania y Cataluña durante la Alta Edad Media [A. UDINA ABELlÓ, La successió testada a la Catalunya altomedieval, Barcelona, Fundació Noguera, 1984, p. 32].

49 Los elemosinarii aparecen mencionados por primera vez en un códice de finales del siglo IX que procede de Ripoll y contiene fragmentos enteros del Liber Iudiciorum [ACA, Códices de Ripoll, 74. Edit. Z. GARCíA VILLADA, Formularios de las bibliotecas y archivos de Barcelona, «Anuari de l'Institut d'Estudis Catalansn, 4 (Barcelona, 1916), pp. 536- 541]. El capítulo III lleva el título de Prologus testamenti y constituye un modelo del testamento, basado en el Derecho visigodo, que consigna el nombramiento de ejecutores pero no contempla la institución de heredero. Los elemosinarii - como indica su nombre- tenían la función de distribuir y administrar las limosnas pro anima, lo cual les confería un gran poder ya que las donaciones pías no se referían a sumas, más o menos considerables, de dinero en metálico, sino que comprendían también la transmisión de heredades, fincas, casas y bienes inmuebles en general. Recuerdan notablemente a sus antecedentes directos: el familiae emptor romano y el salmann germano y su evolución, hasta llegar a los albaceas del siglo XIV, ha sido objeto de la atención de algunos historiadores del Derecho [Ver J. BASTIER, Le testament en Catalogne, pp. 408-417. M. ALONSO LAMBÁN, Las formas testamentarias en la Alta Edad Media de Aragón, «Revista de Derecho Notarial», 5-6 (Madrid, 1954), pp. 7-196; y 9-10 (Madrid, 1955), pp. 241-399. A. GARCí GALLO, Del testamento romano al medieval. Las lineas de su evolución en España, "Anuario de Historia del Derecho Español», 47 (Madrid, 1977), pp. 425-497. F. DE ARVIZU Y GALARRAGA, La disposición umortis causay en el Derecho espantol de la Alta Edad Media, Pamplona, Edics. de la Universidad de Navarra, 1977].

so Según M. Riu, en estas comarcas, los invitados al banquete realizan aún ciertos ritos antes de sentarse a la mesa, como la ablución [M. RIU, Alguns costums funeraris, p. 36]. 
sino más bien a eclesiásticos y comunidades religiosas, con el objetivo evidente de conseguir la salud del alma. El marco de celebración se ha trasladado, pues, de los refectorios de conventos y monasterios a la casa del difunto, con lo cual se mantiene la costumbre pero varían los comensales.

Las fuentes documentales ofrecen una gran muestra de legados destinados a proveer la mesa de los clérigos barceloneses, que permiten conocer la práctica generalizada de este mecanismo, la cantidad asignada y la institución beneficiada. En ocasiones el otorgante especifica que el banquete se celebrará el día de su entierro, o un día después, aunque desgraciadamente no suele aludir a la naturaleza o calidad de las viandas y manjares y se limita a concretar las razones que le mueven a ordenar el legado. Una relación, más o menos detallada, de los alimentos ofrecidos ese día aportaría sin duda datos muy precisos acerca de los hábitos alimenticios del hombre bajomedieval y ampliaría los conocimientos actuales sobre la relación existente entre la dieta y la salud del individuo".

En fin, los barceloneses practican la costumbre de legar dinero para dotar de alimentos las despensas de conventos y monasterios que gozan de su fervor. En ocasiones estos donativos se entregan únicamente a la institución que procederá a acoger sus restos mortales, para que presbíteros y frares celebren el banquete en su memoria; pero frecuentemente se amplía el número de legatarios y la lista se hace interminable, favoreciendo a la mayor parte de comunidades religiosas y hospitalarias de la Ciudad Condal.

También se da la circunstancia de que una casa o convento recibe en exclusiva la dádiva del testador, a cambio de aumentar de manera notable el número de banquetes. De este modo la comunidad beneficiada detentará en solitario los fondos y no compartirá, por tanto, el legado, pero durante los días siguientes al entierro del donante deberá celebrar frecuentes y, casi siempre, bien surtidos banquetes en memoria de la generosidad del difunto $\$ 2$.

Al igual que sucede con la celebración de misas pro anima, la asignación de cantidades en metálico destinadas a banquetes y reparto de alimentos no es una costumbre litúrgica practicada únicamente por una clase social determinada, sino

31 Disponemos de innumerables testadores que ordenan legados en este sentido. El primer caso documentado data de 1309 y corresponde a una barcelonesa, natural de Berga, que cede 50 ss. para que las monjas de Santa Maria de Jonqueres celebren una comida el día de su entierro [ $\Lambda C B, N, B V, M T$, ff. lv-2v], mientras que el último es ordenado por Arnau Burrull, hebdomadario del monasterio de Sant Pere, quien lega $8 \mathrm{ss}$. con destino al banquete anual de la comunidad, que coincidirá con el aniversario de su muerte [Ibidem, ff. 162v-164r]. Nos encontramos pues ante una manifestación ceremonial muy similar a la celebración de aniversarios regulares por el bien del alma, mediante la cual el causante se asegura las oraciones y bendiciones de la comunidad religiosa que resulta favorecida con su legado. Entre ambos testamentos encontramos un gran número de barceloneses que practican este remedio: en 1312 el blanquer Pere Noguera destina 50 ss., beneficiando a franciscanos y dominicos [Ibidem, ff. 28r-29r]; en 1315 Guillema Ballestar entrega 10 ss. a la abadesa de Sant Pere [lbidem, ff. 2v-3r]; en 1318 Arnau Refechs reduce la suma a 5 ss. y ruega a las monjas de Jonqueres que el día del banquete le recuerden en sus oraciones [Ibidem, ff. 194v195r]; Guillem Arenys, de la parroquia de Sant Esteve de Parets, separa el mismo año tres sumas de distinto valor para el banquete de las comunidades de Sant Pau del Camp, Sant Pere de les Puelles y Montserrat [1bidem, ff. 93v95r].

32 Clara Refechs, en 1321 , ordena a sus albaceas que durante los 30 días siguientes a su muerte procuren alimentos a franciscanos y dominicos, aunque su generosidad está teñida de interés ya que los frares, a cambio, rezarán por su alma y celebrarán misas a lo largo de este tiempo [lbidem, ff. 77r-81v]. 
que aparece en los testamentos de un amplio espectro humano -clérigos, nobles, menestrales, cavallers o comerciantes en general-, lo cual evidencia su arraigo entre la ciudadanía y su eficacia a la hora de preparar la salud del alma.

\section{I.3.2 La celebración de aniversarios}

Entre los actos programados por los testadores barceloneses con un plazo de aplicación post mortem destaca la preocupación por perpetuar su memoria entre los vivos y activar así las oraciones de la población religiosa de la ciudad. Este deseo se manifiesta a través de la institución del día de la muerte y su vigencia se extiende, generalmente, a lo largo de una o dos generaciones. El mecanismo utilizado es simple y consiste en la asignación de cierta cantidad de dinero, o de rentas y censos, a una persona de confianza -que suele ser un albacea- con el encargo de que se destine al rector de una parroquia o altar determinado para la celebración de misas anuales que coincidirán con el día del fallecimiento. De esta forma las oraciones y rezos no se agotan con el ritual de la misa funeral sino que se prolongan más allá de la desaparición física del otorgante, lo cual constituye un hecho sacramental que aún existe en la actualidad.

La dotación económica de esta celebración se efectúa mediante los legados en metálico especificados en testamento, aunque a menudo el dinero se suple por la cesión periódica de una parte de las rentas percibidas por las bonors y fincas enfitéuticas. En tal caso el responsable de las celebraciones recibirá la subvención en especies (un par de gallinas, capones, cierta cantidad de vino, aceite, cereales, etc.) o en morabetinos censales ${ }^{33}$.

Los barceloneses suelen mostrarse bastante minuciosos a la hora de consignar en testamento los detalles concernientes a estos aniversarios y suministran una gran cantidad de datos acerca de la parafernalia que va a rodear su futura ejecución: lugar de celebración, número de oficiantes, origen y naturaleza de los fondos destinados a su realización e incluso la personalidad del encargado de velar por la materialización de sus disposiciones. En efecto, los cirios a encender ese día y el mayor o menor número de clérigos celebrantes, según los recursos económicos de cada uno, son objeto de la atención de una ciudadanía dispuesta a invertir su dinero en la salud del alma y evitar así el riesgo de la condenación ${ }^{34}$.

53 Antic Naguía, en 1300, encarga a sus albaceas que asuman la ejecución de su aniversario en la iglesia de Santa Maria de Martorell, asignando a tal efecto los 2 pares de gallinas que recibe anualmente por Navidad [ 16 idem, ff. 6r-7r]. En 1332 Francesca Romeu, la viuda de Guillem Llull, desea que se celebre en los Framenors y destina 4 mbs. que percibe cada año por un manso que posee en alodio en el término de Sants, junto a la casa fortificada de su hijo Romeu [lbidem, ff. 1 16r-118r]. Guillem Cerdà, el hebdomadario de Sant Pere, ordena la compra de 2 mbs. para financiar los gastos de su aniversario [lbidem, ff. 101v-103r]. Sibil.la, doméstica de Ot de Montcada, quiere que el suyo se celebre en Santa Anna y decide invertir $10 \mathrm{lbs}$. en la compra de $1 / 2 \mathrm{mb}$. in loco idoneo [lbidem, ff. $11 \mathrm{5r}-116 \mathrm{r}$ ]. Estàcia, viuda del jurisperito Berenguer Descortell, cursa instrucciones para la adquisición de $1 \mathrm{mb}$. (a razón de 20 lbs.) que rentará anualmente los 9 ss. destinados a la abadesa de Sant Damià, la cual dispondrá el aniversario el 8 de noviembre de cada año [lbidem, ff. 159v-160v]. Y, por último, Pere Desplà, en 1334, ordena a los ejecutores testamentarios la compra de 3 mbs. para sufragar los gastos de 18 presbíteros que oficiarán 3 aniversarios cuatrimestrales el día de Sant Jaume [lbidem, ff. 181r-v].

34 El aniversario de Antic Naguía, por ejemplo, correrá a cargo de 6 presbíteros y cada uno de ellos recibirá la 
Para asegurar la continuidad del aniversario no queda más remedio que asignar una renta fija y segura, ya que el dinero en metálico puede sufrir depreciaciones o acabar en manos ajenas a los responsables de la financiación de los gastos anuales. Por este motivo el mecanismo comúnmente utilizado consiste en la adquisición de rentas inmobiliarias, cuya recaudación y distribución correrá generalmente a cargo del heredero universal, los albaceas o cualquier persona de confianza designada al efecto. En la mayoría de casos se trata de la compra de un morabetino anual (equivalente a 9 ss.) que cubrirá los gastos litúrgicos y será puntualmente entregado al encargado de la celebración.

El desembolso que supone la adquisición de $1 \mathrm{mb}$. a lo largo del período que cubren los testamentos estudiados constituye una fuente económica inestimable, por cuanto permite seguir la evolución de los precios y el aumento del coste de la vida. Las disposiciones de los barceloneses ponen de manifiesto que a principios del siglo 1 mb. vale $15 \mathrm{lbs}$., mientras que en la década de los 30 su precio ha subido hasta las 20 lbs.; es decir, en 30 años se ha experimentado un aumento del 0'75, o lo que es igual: si en 1300 con 100 ss. de inversión se obtenían 3 ss. de renta, en 1330 estos 100 ss. generan tan sólo 2 ss. y 3 ds., de forma que para conseguir un censo anual de 9 ss. ( 1 mb.) se ha pasado de un desembolso de 300 a 400 ss. en poco más de un tercio de siglo".

La mecánica de los aniversarios post mortem, al igual que las misas de difuntos, constituye una manifestación más de la mentalidad de los ciudadanos de Barcelona, empeñados en conseguir la salvación de sus almas y evitar así los horrores del infierno. Al parecer se trata de una práctica generalizada entre las capas altas de la población -capaces de acceder a la compraventa de rentas y censos-y priva en el seno de determinados colectivos, alcanzando gran difusión entre los clérigos y demás representantes de la Iglesia, que se equiparan así a los milites y miembros de la alta burguesía ${ }^{36}$.

Este ritual es, además, objeto de una especial atención por parte del elemento femenino de la ciudadanía barcelonesa, si nos basamos en la documentación consultada, y se da con frecuencia en el seno de familias pertenecientes a la oligarquía municipal (Bellvís, Marimon, Palau, Gruny, Ricart, Llull) y a la nobleza (Vilanova, Sentmenat, Mediona, Cervelló), aunque no faltan ejemplos representativos de su aceptación por parte de los estratos más favorecidos de la burguesía mercantil (Soler, Sala, Bellveí, Descortell, etc.), dotada de unos recursos financieros que no han cesado de aumentar desde mediados de la centuria anterior merced a la política expansiva de la Corona de Aragón y la apertura de nuevas vías marítimas.

suma de 8 ds. Además, su heredero universal entregará una casulla blanca al rector de Santa Maria de Martorell - donde se celebrará el acto- y le suministrará el pan y el vino a utilizar en la misa [Ver supra, nota 53]. El aniversario de la muerte de Sibil.la, viuda del miles Ramon de Vilanova, por su parte, será oficiado por 8 clérigos que vestirán casulla, alba y amito bordados en oro [lbidem, ff. 85v-87r].

ss En 1303 el cantero Pere Dosrius ordena la compra de $1 \mathrm{mb}$. por el precio de $15 \mathrm{lbs}$. [1bidem, ff. 3r-4r], mientras que en 1332 los albaceas de Sibil.la, servidora de Ot de Montcada, pagarán ya 20 lbs.; precio que se mantiene en 1334, cuando Estàcia Descortell dispone la liturgia de su aniversario [Ver supra, nota 53].

36 Es el caso de Guillem Mestre, rector de Sant Miquel, quien encarga un aniversario a celebrar por 6 presbíteros [Ibidem, ff. 143r-144v], o de Arnau Burrull, hebdomadario del monasterio de Sant Pere, que se inclina por una celebración semestral y pide la asistencia de 12 clérigos [Ibidem, ff. 162v-164r]. 


\section{OBRAS PÍAS Y LIMOSNAS}

Los barceloneses del primer tercio del siglo XIV muestran, en líneas generales, una gran inclinación hacia las limosnas y obras de caridad, convencidos sin duda de que representan un medio muy adecuado para asegurarse el favor divino. Por tal razón los legados píos se convierten en verdaderos protagonistas de algunos testamentos, donde aparecen minuciosas listas de parroquias, hospitales, monasterios, clérigos, monjas, menesterosos y enfermos, dignos de recibir la generosidad de los ciudadanos mejor dotados económicamente. El testador, junto a estos legados de caridad, no olvida consignar la identidad del heredero universal y procede además a dictar las instrucciones oportunas para que se cumplan sus últimas voluntades, de modo que las sumas estipuladas lleguen a su destino.

A grandes rasgos, las obras pías que con mayor frecuencia realizan los barceloneses trecentistas se pueden dividir en cinco grupos: asistencia a pobres y menesterosos, redención de cautivos, dotación a muchachas casaderas, financiación de hospitales y, por último, institución de presbiteratos. Estos rasgos de generosidad quedan reflejados en las fuentes consultadas, hasta el extremo de su sistemática reiteración, y es corriente que los testadores ordenen legados en concepto de ayuda a cualquiera de estos sectores deprimidos de la ciudad, aunque no faltan las escrituras donde su titular atiende globalmente a todo el conjunto, sin especificar la cantidad asignada a cada uno pero haciendo hincapié en que los fondos sobrantes, una vez distribuido el total entre los beneficiados -según el criterio de albaceas y herederos-, servirán para cubrir los gastos del sepelio.

De esta forma el estudio del comportamiento caritativo de los barceloneses pone de manifiesto una de las vertientes más interesantes de los esquemas mentales de la población, muchos de cuyos representantes se empeñan en acallar la mala conciencia provocada por las ofensas e injurias cometidas en vida a base de utilizar sus recursos monetarios en un postrero acto de compensación.

Esta conducta representa, una vez más, el exponente de una mentalidad que se define por su uniformidad. Los barceloneses, enfrentados a la muerte, se lanzan a una frenética actividad benefactora sin distinción de clases o sexos; solamente la desigual distribución de la riqueza marca las diferencias entre los legados píos establecidos por los miembros de los estamentos que integran los diversos peldaños de la pirámide social.

\section{II.1 La asistencia a los pobres}

La ayuda a los necesitados se cumple, en general, mediante los legados en metálico, aunque también se suelen establecer donaciones específicas, consistentes en prendas de vestir y ropa de cama -que son, casi siempre, aquéllas que usó en vida el causante-, e incluso se acude a una fórmula intermedia, como es la cesión de una pequeña cantidad de dinero acompañada de la orden expresa de que los albaceas compren túnicas, capas o camisas «para cubrir la desnudez de los pobres vergonzantes».

Este proceder se refleja perfectamente en algunos de los testamentos consulta- 
dos, donde el legado va acompañado de minuciosos detalles acerca de la situación y personalidad de los pobres favorecidos, convirtiéndose por ello en una inestimable fuente de información sobre aspectos urbanísticos, económicos y sociales gracias al interés que el otorgante de la escritura demuestra a la hora de decidir el futuro destino de sus bienes".

Junto al dinero en metálico y las prendas de vestir, nuevas o usadas, encontramos a menudo la provisión de alimentos, lo cual constituye una variedad más de este tipo de legados píos ${ }^{38}$; pero quizás la ayuda más cuantiosa que reciben las bandas de desheredados urbanos procede de las instituciones religiosas (parroquias, conventos, monasterios, hospitales) que se erigen en depositarias y administradoras de los fondos que los barceloneses destinan para aliviar la situación de unos conciudadanos que carecen de cualquier medio de subsistencia y se ven forzados a vivir a costa de la beneficencia.

En ocasiones la generosidad de los testadores no se limita a los legados, más o menos cuantiosos, sino que llega al extremo de traspasar la totalidad de los bienes a los pobres de la ciudad, que pasan así a convertirse en herederos universales de alguien que carece de descendientes y ha llevado a cabo esta designación de forma directa o, en último grado, a través de las fórmulas sustitutorias que contempla la ley. No escasean, en efecto, los causantes que declaran heredero universal al cónyuge supérstite y añaden la sucesión a seguir en caso de la muerte de éste, finalizando esta prelación con el nombramiento de los pobres y necesitados. De este modo, si se da la circunstancia de que a la muerte del testador no sobrevive ninguno de los que forman la cadena sustitutoria, la herencia pasará a poder de la Iglesia, que deberá cumplir las últimas voluntades del fallecido y procederá a distribuir los bienes legados -o el fruto de su venta- entre los estratos más humildes de la población.

Generalmente el donante tiene la precaución de elegir albaceas que proceden de los círculos ciudadanos dedicados a la asistencia y cuidado de los menesterosos, no sólo con la seguridad de que se trata de los más capacitados para repartir equitativamente sus bienes sino también influenciados por la convicción de que sus órdenes

57 Una muestra de la minuciosidad de los barceloneses, en este sentido, la encontramos en los testamentos de Clara de Santquirçe, mujer del notario Francesc Refechs, y de Romeva, viuda del sastre Guillem Ram. La primera lega 12 ds., en 1321, a cada uno de los pobres que, el día de su muerte, se encuentre en la zona comprendida entre el hospital de Sant Joan y el portal de la nueva muralla que se construyó junto a Santa Maria de Jonqueres, otros 12 ds. a los que viven entre la casa de su marido y Sant Pere y, por último, igual cantidad a todos aquellos que practican la mendicidad desde el principio de dicha calle hasta la torre dels Ermiters. Además, ordena a sus albaceas que adquieran 4 piezas de paño morado por valor de $4 \mathrm{ss}$. cada una para proveer de camisas y calzones a un menesteroso, así como una camisa de lino destinada a una mujer sin recursos [ 1 bidem, ff. 77r-81v]. En 1331, la segunda, deja 50 lbs. para vestir al mismo número de indigentes; es decir, 20 ss. para cada pobre, con lo cual nos indica que destina 1 lb. para la confección de cada vestimenta. De cualquier modo, Romeva parece no confiar en el criterio de sus albaceas, a la hora de seleccionar a los favorecidos, y procede, ella misma, a enumerarlos individualmente, especificando las ropas y el calzado que recibirá cada uno (capa, túnica, sobretúnica, camisa, camisola, calzones, zuecos, cáligas, etc.) [lbidem, ff. 60v-64v].

s8 En 1331 el notario Miquel d'Antiga, propietario de mansos y tierras de labor en el Baix Llobregat, dispone que sus albaceas suministren pan y vino a 3 necesitados [ 1 bidem, ff. 50r-53r] y años antes, en 1308, una menestral llamada Sibil.la Calvet se decide por ordenar la entrega de 1 sumada de pan a cada pobre que durante los días inmediatamente posteriores a su muerte acuda a la puerta de su domicilio [lbidem, ff. 9r-11v]. 
serán ejecutadas sin dolo ni engaño. Esta función de confianza recae de forma abrumadora sobre los procuradores de la Almoina de la Catedral, que adquieren en este sentido un verdadero protagonismo respecto a otros miembros de la Iglesia ". La práctica de esta costumbre, a lo largo de todo el siglo, va a permitir que importantes sumas de dinero sean administradas por los procuradores de la Almoina, que pasan a ser los verdaderos intermediarios entre benefactores y beneficiados. Este papel, además, va a potenciar la entrada de la institución catedralicia en el mundo de los negocios y de las transacciones inmobiliarias, ya que con mucha frecuencia las fincas urbanas o rurales de los testadores deben ser vendidas, arrendadas o alienadas con el propósito de obtener rentas y capital suficiente para cumplir las últimas voluntades del otorgante.

\section{II.2 La redención de cautivos}

La donación de fondos destinados a conseguir la libertad de los barceloneses que sufren cautiverio en tierras lejanas es una manifestación más de la mentalidad piadosa de la población de principios del siglo XIV y la suelen practicar los mercaderes ultramarinos, marineros, armadores, patrones, pilotos y, en definitiva, todos aquellos que de un modo u otro conocen los peligros de la piratería, el corso y la hostilidad de los musulmanes peninsulares o del Norte de África.

Los barceloneses, al igual que el resto de la población de la Corona de Aragón, corren el riesgo de perder su libertad en el curso de su participación en las diferentes campañas militares y expediciones organizadas por el monarca, con lo cual se convierten en prisioneros de guerra y su situación puede prolongarse durante varias décadas. Pero también pueden caer en cautiverio en el mar, en el desempeño de sus actividades náuticas y comerciales, con lo cual sus condiciones de vida no son mejores que las de aquellos que fueron hechos prisioneros en el campo de batalla. Tanto unos como otros van a adquirir un status muy próximo a la esclavitud y su única esperanza de libertad pasa por la posibilidad de reunir la cantidad exigida como rescate, la cual será liquidada mediante el concurso de los frailes mercedarios y trinitarios ${ }^{60}$.

39 Son muy numerosos los testadores que encargan el reparto de sus bienes a los procuradores de la Almoina, como Ferrer Ballaró [Ibidem, f. 35r-v] o Sibil.la Oliveres [Ibidem, f. 1r-v]. El primero se limita a ordenar que sus bienes vayan a parar a manos de los pobres, pero la segunda declara heredera universal a su hija Jaumeta mientras viva de forma decorosa, ya que en caso contrario -recurriendo al mecanismo de la cláusula sustitutoria- los procuradores de la $\mathrm{\Lambda lmoina}$ adirán la herencia y la destinarán a obras de caridad. La labor asistencial desempeñada por la Almoina barcelonesa ha sido estudiada, entre otros, por Josep Baucells, archivero de la Catedral de Barcelona [La Pia Almoina de la Seo de Barcelona. Origen y desarrollo, « $\Lambda$ pobreza e a assistência a os pobres na Península Iberica durante a Idade Média (Actas das I Jornadas Lusoespanholas de História Medieval), I, Lisboa, 1973, pp. 73-136; y también, Ginesi de la Pia Almoina de la Sen de Barcelona: els fundadors, «La pobreza y la asistencia a los pobres en la Cataluña Medievalw, I, Barcelona, CSIC, 1980, pp. 17-75].

60 La redención de cautivos y el importante papel desempeñado por ambas órdenes ha sido estudiado por un amplio sector de la historiografía nacional y extranjera [Ver J. M. RAMOS Y LOSCERTALES, El cautiverio en la Corona de Aragón durante los siglos XIII, XIV y XV, Zaragoza, 1915. M. MITJA, L'Orde de la Mercè en el regnat de Joan I, «Cuadernos de Arqueología e Historia de la Ciudad», 9 (Barcelona, 1966), pp. 6-89. CH. VERLINDEN, L'Esclavage dans la Péninsule lbérique du XIVe siècle, «Anuario de Estudios Medievales», 7 (Barcelona, 1971), pp. 577-591. M." T. FERRER, La redempció de cautius a la Corona catalano-aragonesa (segle XIV), albidems, 15 (Barcelona, 1985), pp. 237-297]. 
En general, los testadores barceloneses establecen legados anónimos para la redención de cautivos desconocidos mediante una fórmula sencilla que pretende tan sólo consignar la suma legada, dejando los detalles puramente formales al criterio de los albaceas. La condición social de los otorgantes es muy homogénea y se circunscribe claramente al mundo de los negocios y al ámbito mercantil de la Ciudad Condal, aunque no faltan menestrales y profesionales liberales que adoptan este tipo de obra pía ${ }^{61}$. La cantidad ordenada varía, por otra parte, según la condición social y la actividad laboral del testador, pero se observa una tendencia, muy acusada en el seno de determinados colectivos, a fijarla en torno a los 12 ds.. En efecto, la mayoría de causantes que se integran en las capas trabajadoras de la ciudad se limita a legar 1 s. o incluso $6 d s$., mientras que las gentes del mar amplían su caridad hasta los 3 ó 5 ss., los mercaderes y armadores de nau hasta 10 ó 15 ss. y las damas de la nobleza llegan hasta la nada despreciable suma de 50 ss. ${ }^{62}$.

\section{II.3 Dotación a muchachas sin recursos}

La ayuda a doncellas que carecen de fortuna, con objeto de que abandonen así el celibato, constituye una acción caritativa y social ampliamente practicada por los testadores barceloneses. En realidad no se trata más que de una dotación en metálico consignada bajo la forma de legado y transmitida a su destinataria por mediación de la Iglesia, en cuanto depositaria de los bienes del difunto benefactor.

La manera de hacer llegar esta dotación económica a las beneficiadas corre a cargo, siempre que el donante no se pronuncie en otro sentido, de la parroquia correspondiente, receptaria previa de los fondos entregados por los albaceas o herederos, la cual distribuirá el dinero según las necesidades de sus feligresas. Pero, en determinadas circunstancias, los causantes especifican los nombres de las muchachas, debido quizás a falta de confianza en la gestión de albaceas y rectores parroquiales o, simplemente, por el hecho de conocer personalmente a las doncellas necesitadas de ayuda. Es posible incluso que en todo ello intervengan factores de tipo

61 Practican estos legados, sobre todo, los mercaderes ultramarinos, como Francesc Eiximenis [ACB, N, BV, MT, ff. $171 \mathrm{r}-173 \mathrm{v}$ ], Guillem Sitges [lbidem, ff. 46r-49v], Francesc Sacosta [lbidem, ff. 110r-111v] o Bernat Cervera [Ibidem, ff. 97r-99r]; y también los marineros, como Guillem Bonacasa [lbidem, f. 22r-v], Clara, hija del barquero Ramon Puig y mujer del marinero Romeu d'Argila [lbidem, ff. 14v-15r]; y Elisenda Forner, casada con el también marinero Ramon Sunyer [16idem, ff. 40r-41v]. Junto a ellos se sitúan los miembros de los sectores manufactureros que han experimentado un mayor desarrollo, como el blanquer Guillem Montpedrós [ 16 idem, ff. 12r-v] o el batidor de fustanys Bernat Rubí [lbidem, ff. 4v-5v]. Pero no faltan muestras de la mentalización de los barceloneses respecto a la redención de sus conciudadanos entre determinados colectivos profesionales, como en el caso del jurista Berenguer Descortell [Ibidem, ff. 53r-56r]; en el seno de la Iglesia, como el presbítero Guillem Haubert [Ver supra, nota 23] o el rector de Sant Joan Despí, Jaume Martí [lbidem, ff. 38r-39v]; o entre los distintos niveles de la nobleza de sangre y de servicios, como Saurina de Sentmenat, mujer del consejero real Berenguer de Sentmenat y sobrina del influyente Vidal de Vilanova, comendador mayor de la Orden de Uclés en Montalbán [1bidem, ff. 167r-168v], y la propia Brunissenda de Cervelló [lbidem, ff. 29v-31r].

62 Tanto Guillem de Montpedrós como Bernat de Rubí dejan 12 ds., al igual que el grueso de la menestralía. Elisenda Forner destina 3 ss., Clara Puig 5 ss. y Guillem Bonacasa no determina la cantidad, confiando en el criterio de sus albaceas. Francesc Eiximenis y su cuñado Francesc Sacosta, ambos mercaderes y hombres de negocios, establecen mandas de 20 ss. Saurina de Sentmenat y Brunissenda de Cervelló, evidenciando así su potencial económico, ordenan sendos legados de 50 ss. [Ver supra, nota 61]. 
moral, antes que connotaciones sociales - como señalaba Michel Mollat- ${ }^{63}$, en el sentido de que el benefactor pretende que su beneficiada no incurra en una vida licenciosa y de perdición y la dota de fondos para que pueda formar una familia y vivir honestamente.

Estamos, pues, ante una obra de caridad ejercida de manera particular por la ciudadanía -a través de los legados testamentarios o de las limosnas- ya que, en el primer tercio del siglo XIV, no parece posible hablar de actuación pública al respecto. Es difícil documentar la existencia de algún tipo de centro de acogida de doncellas casaderas en Barcelona, donde recibirían la dote que les permitiría contraer matrimonio, como el que se fundó en Lérida en torno a 1303. Según los estudios de Teresa Vinyoles no se puede hablar de actuación municipal, en este sentido, hasta bien entrado el siglo $\mathrm{XV}^{64}$.

Los ejemplos de la piedad de los barceloneses se reflejan en los testamentos consultados, aunque casi siempre lo hacen de forma genérica, sin especificar el nombre de las doncellas beneficiadas ${ }^{65}$. Además, es muy difícil precisar la suma legada con exactitud ya que ésta se engloba en los fondos destinados a la sepultura y los funerales del otorgante ${ }^{66}$.

Se puede también dar la circunstancia de que la ayuda recaiga sobre muchachas anónimas, aunque pertenecientes a la familia o el mundo cotidiano del testador. Nos encontramos entonces ante una fórmula ecléctica, pues por un lado el otorgante desconoce la identidad individualizada de las beneficiadas, pero por el otro tiene la certeza de que se integran en su mismo sector social y laboral. Son abundantes, a tal efecto, los barceloneses que legan su dinero a doncellas por casar y especifican que sean seleccionadas entre las féminas de su familia (de genero meo).

Señalaremos, por último, que esta manifestación de la caridad de la población de la Ciudad Condal corre a cargo mayoritariamente de los ciudadanos encuadrados en las filas de la menestralía, y sobre todo a cargo de las viudas de individuos que en vida pertenecieron a los sectores manufactureros de la ciudad, sin olvidar a las damas de la nobleza y del grupo de los milites.

63 Les pawrres et la société médiévale, «Actes du XIIle Congrès International des Sciences Historiques», I, Moscou, 1970, p. 234.

64 Ver T. VINYOLES, Les barcelonines a les dameries de l'Edat Mitjana, Barcelona, Fundació Salvador Vives Casajuana, 1976, pp. 83-91; y también, Ajudes a donzelles pobres a maridar, «La pobreza y la asistencia a los pobres en la Cataluña medieval», I, Barcelona, CSIC, 1980, pp. $295-362$.

65 En 1315, Saurina Verdera, mujer de Ramon Burrull, residente en el barrio de Sant Pere, deja 15 lbs. para repartir entre misas, obras pías y casar muchachas, ad cognitionem dictorum manumissorum meorum [ACA, C, BV, MT, f. 23r-v]; en 1322, Guillem de Vallseca, sobrino del prestigioso jurisperito Francesc de Vallseca, deja un legado para obras pías, una parte del cual será pro puellis pauperibus maritandis, sin especificar el número o los nombres [Ibidem, ff. 99r-101v]; y, en 1334, el fariner Simó Guaita reparte un legado entre las doncellas sin medios y los pobres vergonzantes [Ibidem, ff. $131 \mathrm{v}-132 \mathrm{r}$ ].

66 Guillem de Vallseca separa 3.000 ss. pro anima mea et sepultura et pro lexiis piis infrascriptis faciendis. La cantidad sobrante, una vez pagados los gastos funerarios, se repartirá grosso modo entre otras obras caritativas. Saurina Burrull desea que la dotación a las doncellas salga de las 15 lbs. que separa por el mismo concepto, mientras que Simó Guaita dobla la suma a 30 lbs., que se repartirán entre los pobres y las muchachas (Residuum vero dictarum triginta librarum, facta mea sepultura et solutis et completis omnibus et singulis supradictis, volo quod per dictos manumissores meos pauperibus verecundis et puellis pauperibus maritandis et aliis piis causis ad cognitionem ipsorum manumissorum meorum erogari). 


\section{II.4 La financiación de bospitales}

El hecho de establecer legados con destino a la caja de las diversas instituciones hospitalarias de la ciudad constituye una costumbre muy arraigada entre la población de Barcelona. Esta manifestación de caridad, de cualquier modo, no es exclusiva del período estudiado sino que se trata de una práctica que proviene de tiempos anteriores y que experimenta una rápida difusión a partir de la aparición de las Órdenes Mendicantes (dominicos, franciscanos, mercedarios, penitentes, etc.), las cuales ejercerán una gran influencia en el espíritu y la mentalidad de la ciudadanía mediante la predicación y el exhorto a la realización de obras piadosas.

Los barceloneses legan cantidades importantes de dinero con destino a la asistencia sanitaria de los enfermos sin recursos, pero casi siempre optan por una donación genérica que se refiere a todos los hospitales situados en el recinto urbano ${ }^{67}$. Los centros que reciben la ayuda post mortem de los testadores no son excesivamente numerosos y su creación obedece, en general, a la iniciativa privada de particulares -laicos o eclesiásticos- de relieve, por lo cual se les conoce popularmente con el nombre de su fundador ${ }^{\star}$.

La difusión de estos legados queda perfectamente reflejada en las fuentes documentales, hasta el extremo de que más de la mitad de los testadores deja parte de sus bienes a cualquiera de los hospitales citados -0 a su conjunto, según el criterio de los albaceas y del heredero universal- ${ }^{69}$. Entre ellos se advierte un equilibrio relativo en cuanto al sexo, pues aparecen 57 hombres y 44 mujeres, lo cual indica el grado de aceptación que registra esta costumbre entre la población barcelonesa trecentista ${ }^{70}$.

La cuantía de estos legados es bastante heterogénea pese a que abundan las pequeñas donaciones de $12 \mathrm{ds}$., o incluso de medio sou., pero no faltan ejemplos que denotan una gran liberalidad y la suma puede alcanzar los 10 ss. Las primeras son el fruto de la piedad de los menestrales y bajo clero, en general, mientras que las segundas corresponden siempre a miembros de las ricas familias de mercaderes y banqueros -como Francesc Eiximenis ", Guillem Sitges "2, Jaume Gruny ${ }^{13}$ y Fran-

67 La fórmula usada en estos casos no deja lugar a dudas pues indica la cantidad legada anicumque baspicalivm pasperum Bancbinone of domui imfirmorwm, sin especificar el nombre de ninguno de ellos.

60 A principios del siglo XIV los hospitales barceloneses son cuatro: el de Colom, fundado por el canónigo Joan Colom a principios de la centuria anterior; el del canónigo Pere Desvilar, que se empezó a construir a finales del XIII; el de Pere Desvilar, que se suele confundir con el anterior y lleva el nombre del ciudadano que impulsó su construcción en torno a 1300; y, finalmente, el de Bernat Marcús, financiado por un acaudalado barcelonés, propietario del caseell de Port, en Montjuíc, que formalizó su testamento en 1166 (en el Manual de Bermat de Vilamíbia, el castillo pertenece ya al poderoso miles Guillem de Torrelles). Además de estas instituciones funcionan también el hospital del monasterio de Santa Eulàlia del Camp y la casa dels malaltes o dels masells, que asistía a los leprosos. Respecto al papel desemperiado por cada uno de estos centros hospitalarios, es interesante el trabajo ya citado de C. Batlle y M. Casas [Ver supra, nota 31].

69 Tenemos documentados 101 legados a hospitales sobre un total de 151 testadores, lo cual supone que el 67’33\% practica esta modalidad de limosna.

70 Los porcentajes resultantes son muy elevados ya que representan el $66^{\circ} 27 \%$ de hombres y el $67^{\circ} 69 \%$ de mujeres sobre el total de testamentos vaciados.

7 ACB, N, BV, MN, ff. 171r-173v.

72 lbidom, ff. 46r-49v.

73 lbidem, ff. 121r-123v. 


\begin{tabular}{|c|c|c|c|}
\hline AB̉o & Iogados & Inporte & Centro Hospitalario \\
\hline 1300 & 1 & $12 \mathrm{ds}$. & Enfermos \\
\hline 1303 & 2 & $12 \mathrm{ds}$. & Pobres y enfermos \\
\hline 1308 & 2 & $24 \mathrm{ds}$. & Pobres y enfermos \\
\hline 1310 & 2 & $24 \mathrm{ds}$. & Pobres y enfermos \\
\hline 1312 & 3 & $8 \mathrm{s8}$. & Pobres y enfermos \\
\hline 1313 & 3 & $36 \mathrm{ss}$ & $\begin{array}{l}\text { Desullar, Colom y } \\
\text { Sta. Eulalia Camp }\end{array}$ \\
\hline 1314 & 3 & $30 \mathrm{ds}$. & Pobres y enfermos \\
\hline 1315 & 1 & $12 \mathrm{ds}$. & Pobres y enfermos \\
\hline 1318 & 2 & $18 \mathrm{ds}$. & Pobres y enfermos \\
\hline 1319 & 2 & $15 \mathrm{ss}$. & Pobres y enfermos \\
\hline 1320 & 4 & $5 \mathrm{ss}$. & Pobres, P. Montmelo \\
\hline 1321 & 3 & $4 \mathrm{ss}$. & Pobres y enfermos \\
\hline 1322 & 2 & $6 \mathrm{ss}$. & Pobres y enfermos \\
\hline 1323 & 1 & $12 d s$. & Pobres y enfermos \\
\hline 1324 & 2 & $11 \mathrm{ss}$. & Pobres y enfermos \\
\hline 1325 & 3 & $30 \mathrm{ss}$. & Pobres y enfermos \\
\hline 1326 & 1 & $10 \mathrm{ss}$. & Pobres \\
\hline 1327 & 1 & $6 \mathrm{ds}$. & Pobres \\
\hline 1328 & 4 & $36 \mathrm{ds}$. & Pobres y enfermos \\
\hline 1329 & 4 & $60 \mathrm{ds}$. & Colom, Molins de Rei \\
\hline 1330 & 2 & $24 d s$. & Pobres y enfermos \\
\hline 1331 & 4 & $6 \mathrm{ss}$. & Pobres y enfermos \\
\hline 1332 & 8 & $35 \mathrm{ss}$. & $\begin{array}{l}\text { Pobres y enfermos, } \\
\text { Desvilar y Colom }\end{array}$ \\
\hline 1333 & 7 & $114 \mathrm{ds}$. & Desvilar, Colom, \\
\hline 1334 & 21 & $56 \mathrm{ss}$. & Pobres y enfermos \\
\hline 1335 & 2 & $4 \mathrm{ss}$. & Pobres y enfermos \\
\hline 1336 & 4 & $48 d s$. & Pobres y enfermos \\
\hline 1337 & 5 & $19 \mathrm{ss}$. & Pobres y enfermos \\
\hline 1338 & 2 & $15 \mathrm{ss}$ & Pobres, Colom \\
\hline TOTAX & 101 & 11 1bs. & $588 ., 6$ ds. \\
\hline
\end{tabular}

\section{Cuadro 3: Legados on motálico para hospitales}


cesca Llull- ${ }^{74}$, o a los milites del territorio jurisdiccional de la ciudad -como Arnau de Torrelles- ", sin olvidar naturalmente la generosidad de los representantes de la alta nobleza -como Brunissenda de Cervelló- ${ }^{`}$ o de las altas jerarquías de la Iglesia -como Hug de Cardona-".

La alusión a todos los hospitales y casas de enfermos de la ciudad, como ya dijimos, priva sobre los legados específicos que benefician a una institución determinada. Analizando detenidamente los testamentos de la época estudiada no deja de sorprender que las menciones al hospital de Colom o de Desvilar, por ejemplo, son muy escasas y el causante se limita a dejar sus fondos a las «casas de pobres y enfermos», fórmula estereotipada que contempla una asignación parcial a cada uno de ellos ${ }^{78}$, excepto en el caso de que se exprese algún tipo de rechazo por causas, sin duda, de indole personal -que el notario no considera oportuno plasmar en la escritura- o, al contrario, si se da la circunstancia de que el testador desea favorecer en mayor medida a una institución sin excluir por ello a las demás ${ }^{79}$.

\section{II.5 La institución de presbiteratos}

Nos encontramos aquí con la curiosa fundación, o mejor dicho dotación, de una prebenda, de un beneficio eclesiástico a favor de un individuo -que ostenta la condición de religioso- y que quedará adscrito a un altar determinado para celebrar misas y demás sacrificios por el bien del alma de su patrocinador. Se trata de otra de las actitudes rituales que muestran la homogeneidad mental de los barceloneses, decididos en cualquier momento -y sobre todo a la hora de la muerte- a poner sus recursos materiales a disposición de la Iglesia con objeto de que sus obras de caridad resulten gratas a Dios e inclinen la balanza a su favor.

La mecánica institucional de estos beneficios se asemeja en sus postulados a la celebración de aniversarios ya que no sólo la finalidad es coincidente -ambas prácticas pretenden perpetuar la memoria del difunto entre los vivos-, sino que además la asignación económica procede invariablemente de las rentas y censos enfitéuticos del ordenante.

Disponemos de un buen número de ciudadanos que instituyen beneficios en altares y capillas de Barcelona o del territorio jurisdiccional, aunque la mayoría no cita el nombre de las personas encargadas de ocuparlos. Pese a esta omisión, los

74 Ibidem, ff. 116r-118r.

7s Ibidem, ff. 189r-192v.

76 lbidem, ff. 29v-31r, 31r-v y $31 \mathrm{v}-32 \mathrm{r}$

"Ibidem, ff. 103r-106r, 106r-v y 106v-107r.

78 A lo largo del período de 1300-1338 sólo se citan, de forma esporádica, los nombres de los hospitales de Colom (en 5 ocasiones), de Desvilar (en 3 ocasiones) y de Santa Eulàlia del Camp (en 1 ocasión), de gran raigambre en Barcelona, junto a dos instituciones extrañas a la ciudad, como son las casas de Molins de Rei y de Pere de Montmeló [Ver supra, Cuadro 3: Legados en metálico para hospitales]. Estos dos ejemplos obedecen a la piedad de testadores forasteros, que establecen legados para los centros hospitalarios de sus lugares de origen.

79 El batidor de fustanys Bernat Rubí deja, en 1313, 12 ds. cuilibet hospitali pauperum Barchinone et domui infirmorum, pero hace constar que el hospital de Santa Eulàlia del Camp recibirá 2 ss., doblando así la suma, pese a que sólo han transcurrido unos años desde la malversación de fondos cometida por el rector Descoll [Ver supra, nota 34]. 
testadores se muestran muy explícitos y suministran una abundante y variada información acerca de los altares de su devoción, las sumas anuales asignadas, los deberes y obligaciones de los beneficiados o las medidas a tomar en caso de la negligencia del titular, lo cual sirve para ampliar nuestros conocimientos sobre la condición de los clérigos beneficiados y, por extensión, sobre los comportamientos de la población.

La dotación de los presbiteratos, es decir la renta anual que cubrirá absolutamente todos los gastos (asignación y vivienda del titular, vestiduras y objetos litúrgicos, decoración del altar, etc.) varía según el status social del causante, pero puede alcanzar sumas desorbitadas ${ }^{80}$. Estas rentas van destinadas, generalmente, a los altares de las iglesias situadas en el casco urbano ${ }^{81}$-algunos de los cuales han sido expresamente construidos para la ocasión- ${ }^{82}$ o de las parroquias enclavadas en el territorio ${ }^{83}$.

En ocasiones la institución de este tipo de prebendas eclesiásticas lleva al ordenante a entrar en detalles acerca de la decoración u ornamentación del altar elegido como marco ${ }^{84}$, y utilizar la oportunidad que le brinda la escritura notarial para proceder a la donación, más o menos generosa, de objetos de culto y vestiduras litúrgicas ${ }^{85}$. También cuida con esmero de las aptitudes y capacidad del futuro

80 Como los 400 ss. (algo más de 44 mbs.) que destina el antiguo administrador de Sant Pere, Bernat Soler, en 1321 [ACB, N, BV, MT, ff. 72v-75v ], los 108 ss. ( 12 mbs.) de Brunissenda de Cervelló [Ibidem, ff. 29v-31r], los 300 ss. (33 mbs. y medio, aproximadamente) de Saurina de Mediona [Ibidem, ff. 193r-194v], o los 120 ss. (poco más de 13 mbs.) que el notario Miquel Antiga adjudica al rector del altar de Sant Joan de la iglesia de Sant Vicenç dels Horts [lbidem, ff. 50r-53r].

${ }_{81}$ Bernat Soler elige el altar de Sant Nicolau, del monasterio de Sant Pere, y Brunissenda de Cervelló el de Sant Antoni, de la Catedral [Ver supra, nota 76]. Clara, la mujer del notario Francesc Refechs, se decide por el de Sant Climent, de Santa Maria del Pi [Ibidem, ff. 77r-81 r], y Guillem Mestre, rector de Sant Miquel, por el de Santa Cecilia, de la propia parroquia [Ibidem, ff. 143r-144v]. Los ejemplos son muy numerosos: Santa Tecla, Sant Cosme, Santa Celia, etc.

82 Francesca, viuda de Arnau Codina, ordena en 1334 un beneficio en el altar que ha mandado construir en el claustro de la Catedral de Vic, exigiendo que la titularidad recaiga en algún clérigo de su propia familia [Ibidem, ff. 165v-166r], y Saurina de Mediona, tres años después, destina los citados 300 ss. al altar de Sant Jordi que ordena construir en la Sede barcelonesa si iam non sit constructum [Ver supra, nota 80]. El desconocimiento del interior de la Catedral de que hace gala la noble dama del clan Mediona -al cuestionar la existencia de un altar dedicado a Sant Jordi- es poco menos que sorprendente. Por otra parte es difícil precisar si sus deseos se vieron cumplidos, pues el testamento está fechado en 1337 y la capilla del vencedor del dragón fue fundada por el canónigo Francesc Rufás en fecha incierta, pero sabemos que fue terminada, el año 1373, por Pere Margens, notario de la Cancillería de Pere el Cerimoniós, el cual financió las obras con sus propios fondos [Ver J. MAS, Notes bistòriques del Bisbat de Barcelona, I, Barcelona, Establiment Tipogràfich de Jaume Vives, 1906, p. 79].

83 Jaume Fonts, mercader y hombre de negocios, instituye un presbiterato en la iglesia de Santa Maria, situada en el término de Lliçà, y asigna una cuartera de trigo en alodio, especificando que el laudemio y la fadiga pasarán a su heredero universal de modo que el beneficiado detentará solamente la nuda percepción [Ibidem, ff. $81 \mathrm{v}$ 84r].

84 Es expresivo, en este sentido, el deseo de Clara, la viuda del ex-administrador Bernat Soler, cuando dota un beneficio en el altar de Santa Magdalena, del monasterio de Sant Pere, y pide a la abadesa permiso para derribarlo y construirlo nuevamente de forma más acorde a sus deseos. Si el permiso es denegado, el presbiterato pasará al altar de Sant Nicolau (el mismo que eligió su difunto marido unos lustros antes) y su heredero hará instalar un bello retablo decorado con las escenas de la vida y obras de Santa Magdalena y Sant Nicolau [Ibidem, ff. 183v186r].

85 Brunissenda de Cervelló, por ejemplo, lega en 1326 todos sus cálices de plata al presbiterato que instituye en la Catedral barcelonesa, así como las tablas de madera pintada y los vestidos corporales [Ibidem, ff. 29v31 r]. 
beneficiado, entrando en valoraciones personales acerca de sus obligaciones y de la conducta que deberá observar en el ejercicio de su misión; de tal modo que si incumple formalmente sus deberes, se muestra negligente o vive indecorosamente será relevado de su cargo sin contemplaciones ${ }^{86}$. Por otra parte, una vez establecidas las condiciones impuestas al beneficiado, se procede en ocasiones a ejercer el derecho a designar a la persona más idónea, que suele ser algún miembro de la familia del testador o un mero protegido ${ }^{87}$.

Los ejemplos acerca de la mecánica y finalidad de esta institución, como ya señalamos, son relativamente abundantes y aportan una serie de datos suficiente, cuantitativa y cualitativamente, para su conocimiento. Entre los casos estudiados destaca, quizás, el del miles Roger de Castellcir ${ }^{8}$, cuyo testamento se convierte -no sólo por la minuciosidad en el detalle sino también por la finalidad perseguida- en una verdadera muestra de la mentalidad colectiva de los miembros de la nobleza de armas y de sangre.

El señor de Castellcir formaliza su testamento el 27 de junio de 1309, antes de partir hacia Almería con el ejército de Jaume II, y nombra heredero universal a su hermano Gilabert. Entre los múltiples legados y obras de caridad que instituye no falta la dotación de un presbiterato perpetuo en la capilla de Sant Martí de La Roca, situada en el término del castillo de Castellcir, con objeto de que sirva de sustento a un clérigo beneficiado. Las obligaciones del titular de la prebenda las enumera el propio fundador y se resumen en el compromiso de celebrar a diario una misa de Difuntos y observar las Horas Canónicas, mientras que la intención queda patente en el momento mismo en que Roger especifica que el beneficiado rezará por su alma y por el alma de todos los miembros de la familia que ya fallecieron. La dotación económica no es nada despreciable y va dirigida a la manutención del presbítero y a la compra de objetos litúrgicos (cálices, misales, cruces, rosarios) y vestiduras (amitos, casullas, albas), para lo cual asigna uno de sus mansos con todos sus hombres y mujeres, honors y censos agrarios, además de la fuerte suma en metálico de 1.000 ss.

Pero Roger procura no dejar ningún cabo suelto y, unas líneas más abajo, prevé que el beneficio puede llegar a quedar vacante -por el fallecimiento de su titular-, en cuyo caso la designación del sucesor correrá a cargo del señor de Castellcir, sea quien sea en aquel momento, que pasará por tanto a detentar el ius patronatus de la institución. Lo más curioso es que se advierte cierta reticencia por parte del testador ya que, a continuación, añade que, si el obispo de Vic prohibe este presbiterato o bien intenta nombrar directamente al clérigo beneficiado, las tierras y rentas asignadas revertirán de nuevo al señor de Castellcir.

\footnotetext{
86 Clara Refechs manifiesta que el titular del presbiterato del altar de Sant Climent deberá estar presente en su puesto diariamente, desde el Cántico hasta las Horas Completas, si no se lo impide la enfermedad o cualquier causa justificada. En caso de no cumplir estas obligaciones será fulminantemente destituido e inmediatamente suplido por otro más capacitado [lbidem, ff. $77 \mathrm{r}-81 \mathrm{r}$ ].

87 Francesca Codina ordena que el beneficio recaiga en algún miembro de su familia, según el criterio de sus albaceas [lbidem, ff. 165v-166r], mientras que Clara Refechs o el rector de la parroquia de Sant Miquel [Ver supra, nota 81] amplían la información y nombran a uno de sus sobrinos para ostentar la titularidad de sus prebendas. 88 Ver supra, nota 15.
} 
Todo ello permite conocer de forma precisa la estructura de los presbiteratos y evidencia, además, los intentos de intromisión de las altas jerarquías de la Iglesia en la esfera religiosa privada. No es de extrañar, en este caso, que el obispo de Vic alegue derechos jurisdiccionales sobre las parroquias del término de Castellcir, ya que si consigue controlar el beneficio instituido por Roger pasará asimismo a ser el administrador de las tierras, el dinero y los censos asignados como dotación. De este modo adquiere su verdadera importancia la figura del ius patronatus; es decir, del derecho a percibir las rentas, entregar la parte correspondiente al beneficiado, decidir el cese o sucesión de éste, firmar las escrituras de alienación o compra de las bonors que prestarán censos enfitéuticos y, en su caso, cobrar el importe generado por el laudemio, la fadiga y demás derechos señoriales. En realidad, las funciones del patronus de un presbiterato se asemejan notablemente a las que corresponden al dominus directo de los inmuebles en régimen de explotación enfitéutica.

Esta manifestación de la piedad de los barceloneses de principios del siglo XIV queda, pues, perfectamente reflejada en sus escrituras mortis causa. Los ejemplos hablan por sí mismos y ponen de relieve la difusión de estas dotaciones eclesiásticas en el seno de determinados colectivos sociolaborales, ya que una primera conclusión nos permite asegurar que la adscripción de un beneficio a un altar o capilla corre tan sólo a cargo de los religiosos y de los miembros de la nobleza o de las familias más ricas y poderosas de la ciudad, pero no aparece jamás en los testamentos de los representantes del mundo laboral y artesanal que se integran en la masa de la menestralía ni en las escrituras de los productores del sector primario.

\section{RECONOCIMIENTO DE DEUDAS Y OFENSAS}

Una de las características del hombre enfrentado a una muerte segura, sea ésta próxima o lejana, es la veracidad de sus últimas voluntades. Los engaños, fraudes o atropellos que se cometieron en vida intentan ser perdonados por el Sumo Hacedor y para ello es preciso confesarlos, reconocerlos y, finalmente, resarcir -económica y moralmente- a los acreedores y ofendidos. En este sentido, una vez aceptado el hecho de que todos los testadores se muestran proclives a pregonar sus deudas, resulta obligado preguntarse si esta conducta unánimemente colectiva obedece a causas meramente jurídicas o, al contrario, es el resultado exclusivo de los problemas de conciencia que embargan al causante. En este caso se trataría tan sólo de obtener el perdón divino y esta práctica entraría de lleno en el campo de la mentalidad del individuo, resultando una más de las expresiones del comportamiento adoptado ante la idea de la muerte.

Es obvio que la satisfacción post mortem de deudas, en algunos casos, pretende proteger a los herederos de posibles reclamaciones, evitándoles así pleitos y litigios que sólo conducen a gastos y pueden poner en peligro el patrimonio familiar debido a la obligatoriedad de entregar bienes - muebles o inmuebles- y dinero en concepto de garantía o por cualquier otro inotivo. El débito declarado obedece generalmente a asuntos de negocios, sobre todo de comandas, y el testador pone especial cuidado en ordenar a los albaceas o herederos que recuperen las escrituras y albaranes donde figuran las razones y el valor de la suma impagada en su día. Como es de suponer, 
buen número de los testamentos que reflejan este tipo de deudas corresponde a mercaderes, cambistas y profesionales liberales (apotecarios, médicos, juristas, notarios, etc.). No hay duda, pues, de que no se trata de una cuestión de conciencia sino de una declaración motivada por causas mercantiles o comerciales, cuya liquidación oficial cerrará el camino a las reclamaciones judiciales.

Pero en ocasiones la intención del testador es manifiestamente catártica y el reconocimiento de la deuda o del abuso busca compensaciones espirituales que difícilmente se encontrarán en esta vida. ¿Cómo se explicaría, entonces, que muchos barceloneses recuerden estas ofensas precisamente a la hora de hacer un balance de su vida, momento en que la idea del fuego eterno se hace visible y llena de temor el ánimo de las gentes?

Muchas de tales deudas, por otra parte, se cometieron tiempo atrás, incluso en la época de juventud, hasta el punto de haber olvidado incluso los nombres de los atropellados -como dice sin ambages el arcediano Hug de Cardona- ${ }^{89}$. En este caso, el transcurso del tiempo y la elevada categoría social del deudor reducen las posibilidades de reclamación, de modo que la confesión realizada ante el notario Bernat de Vilarrúbia, el 17 de marzo de 1332 , no es más que un intento por descargar la conciencia de un recuerdo que pesa con exceso.

La declaración de deudas aparece en todos los testamentos de la época; las diferencias radican, solamente, en la mayor o menor minuciosidad y en el empeño que pone el causante en su satisfacción. No siempre se detallan una a una, aportando el nombre del acreedor o la naturaleza de la obligación, pero aparecen indefectiblemente de forma global a la hora de establecer la cantidad destinada para la sepultura y los gastos funerarios ${ }^{90}$. Esta fórmula estereotipada demuestra el reconocimiento de las deudas por parte del testador, pero impide conocer los negocios y transacciones que las originaron. De cualquier modo pone de manifiesto que los barceloneses, enfrentados a la muerte, no excluyen la posibilidad de haber cometido irregularidades pese a no recordarlas, motivo que les lleva a cumplir este postrer acto de purificación.

Nadie está libre de culpa y todos tienen deudas pendientes o se arrepienten de alguna acción reprobable, disponiéndose a liquidarlas ante el temor de que el Creador les pase factura en el más allá. Tales deudas contemplan una gama amplia y diversificada, que se extiende desde modestas compras domésticas hasta comandas y negocios de enorme cuantía, pasando por los préstamos - con o sin interés- y la compraventa de fincas e inmuebles ${ }^{91}$.

Los barceloneses contraen deudas, en primer lugar, por la adquisición de

\footnotetext{
89 Hug de Cardona deja una fuerte cantidad de dinero para que sus albaceas la destinen a aquellos a quienes ofendió, o a sus herederos, pese a que immo nomines eis penitus ignoramus [ACB, N, BV, MT, ff. 103r-106r]

90 En todos los testamentos consta la fórmula Accipio autem pro anima mea et sepultura, destinada a cubrir estos gastos, y a continuación se expresa la voluntad de liquidar deudas, de esta manera: Primo et ante ommia mando et ordino quod debita mea solvantur et iniure mee restituantur.

91 Ejemplo de esta diversidad se encuentra en las deudas que van de los 2 modestos sous, que la viuda de Guillem Vilanova debe a cierto carnicero de Olesa por los víveres que en su día le suministró [ $A C B, N, B V, M T, f f$. 15v-16r], hasta las 40 lbs. que el acaudalado hombre de negocios Guillem Sitges recibió de manos de su albacea Bernat Torrevella, marido de su sobrina Agnès, en concepto de comanda comercial [1bidem, ff. 46r-49v].
} 
prendas personales y ajuar doméstico, como vestidos y calzado (gramallas, camisas, túnicas, zuecos, abarcas), productos alimenticios (pan, harina, trigo, carne, vino, leche) y ropas de cama (colchas, almohadas, mantas), por lo cual la alusión a sastres, zapateros -incluso remendones-, tejedoras, costureras, panaderos, comerciantes de grano, carniceros, vanovers, colchoneros, etc., adquiere unas cotas importantes. En segundo lugar, a causa de préstamos y depósitos -realizados generalmente por la comunidad judía- ${ }^{92}$. En tercer lugar, por la compra de herramientas y útiles de trabajo (yunques, martillos, palas, cepillos de carpintero, recipientes de todo tipo, etc.). En cuarto lugar, a causa del impago de censos, pensiones o alquileres (prestados por los obradores manufactureros o por las viviendas urbanas). Y, finalmente, por los servicios que reciben de los productores y artesanos (alfareros, mestres de cases, candeleros, herreros, carpinteros, plateros, maestros armeros, fabricantes de yelmos y corazas, etc.).

El arrepentimiento, otras veces, no obedece a las deudas insatisfechas sino que responde al recuerdo de algún negocio o transacción comercial poco acordes con la ética y la moral, lo cual hace recapacitar al causante y le impulsa a poner remedio, como es el caso de Jaume Gruny, miembro de una de las familias más poderosas de la alta burguesía barcelonesa, cuando ordena a sus albaceas que devuelvan a una serie de conciudadanos la suma de 2 ss. que cobró a cada uno por libra prestada ${ }^{93}$.

Puede darse la circunstancia, también, de que el deudor consigne la cantidad a liquidar y el nombre del acreedor, pero que no se pronuncie acerca de los motivos que generaron el débito, consciente sin duda de la inutilidad de insistir en un dato que es de sobras conocido por ambas partes involucradas ${ }^{94}$, aunque en general se aprecia una mayor locuacidad por parte de las mujeres, las cuales son más explícitas que sus paisanos a la hora de declarar sus deudas domésticas ${ }^{99}$.

92 El volumen de los capitales que pasan por las manos de los prestamistas judios barceloneses alcanza cifras cuantiosas. Significativos son, en este sentido, los nombres de personajes como Cresques Alfaquí [ACB, N, BV, 1295, f. 80r], Abraham Barbut [Ibidem, f. 84v], Isaac de Bellcaire [Ibidem, f. 85v], David Estruc [Ibidem, f. 41v], Bonjuda Gracià [Ibidem, f. 8v], Vidal Malet [lbidem, f. 85v; ACA, C, reg. 206, f. 32r], Abraham de La Cavalleria [ACA, C, reg. 211, ff. 338v-339r] o Salomó Isaac [ACA, C, reg. 210, f. 96v]. Todos ellos aparecen realizando negocios (comandas, compraventa de fincas, etc.), pero sobre todo prestando dinero con interés a sus conciudadanos cristianos.

93 Jaume Gruny, hijo del difunto Jaume Gruny, ordena su testamento el 16 de agosto de 1332 y declara encontrarse enfermo. Desea ser enterrado en la Catedral barcelonesa y establece innumerables legados piadosos. El lujo de detalles y el óptimo estado de conservación de la escritura permiten conocer datos hasta ahora inéditos acerca de la familia (número de hijos), las propiedades inmuebles (una torre y varios molinos en Santa Coloma), las operaciones comerciales (tiene tratos con mercaderes, drapers y prestamistas de Barcelona y es el gestor de una sociedad mercantil de Montpellier) o sus reclamaciones ante los tribunales de justicia (mantiene un litigio con el obispo de la Ciudad Condal a causa de los bienes de su difunto hermano Pere, de quien es heredero universal) (Ver supra, nota 27]. El clan familiar de los Gruny ha sido estudiado, entre otros, por C. BATLLE y J. BUSQUETA [Las familias de la alta burguesía en el municipio de Barcelona (siglo XIII), "Anuario de Estudios Medievalesw, 16 (Barcelona, 1986), pp. 81-92] y por C. BATLLE et alii [Aproximasio a l'estudi d'un a familia barcelonina els segles XIII iXIV: Els Grony, «Homenaje a la memoria del prof. Dr. Emilio Sáezw, III, Barcelona, CSIC, 1990, doc. 5, pp. 303310].

94 Roger de Castellcir debe 500 ss. a la noble dama Guillema de Montcada, pero no indica las razones. De todas formas el señor de Castellcir se muestra muy cuidadoso con las obligaciones contraídas a lo largo de su vida, pues declara que existe un documento sellado con la relación de sus deudas, que se encuentra depositado en el convento de los Framenors bajo el cuidado de fra Francesc de Vilagrasa [Ver supra, nota 15].

95 Las barcelonesas suelen consignar datos suficientes para facilitar el trabajo a albaceas y herederos, de modo 
Donde realmente se aprecia que la declaración de acciones punibles obedece a motivos de conciencia es en los testamentos de personajes de relieve y prestigio -pertenecientes a la Iglesia, a la nobleza o al mundo del comercio y las finanzas- . La imposibilidad de resarcir económicamente a los perjudicados, ya que generalmente se trata de atropellos y abusos donde no interviene deuda alguna, nos coloca ante una postura anímica, ante una cuestión de autoexpurgación que busca la purificación del alma tras la muerte del cuerpo.

Los ejemplos de esta peculiar mentalidad abundan en la documentación estudiada y no ofrecen dudas, puesto que de no ser así resultaría difícilmente comprensible la intención de algunos causantes cuando confiesan ciertos actos del pasado, como Bernat de Sarrià, señor de Sarrià, que 30 años atrás se apropió de los censos ( 30 cuarteras de aceite, 60 de cebada y 60 pares de capones) destinados al rector del altar de Santa Maria, construido en la iglesia de Sant Vicenç de Sarrià *; Hug de Cardona, que en su juventud despojó a unos payeses de sus cosechas de uva y trigo ${ }^{97}$; Brunissenda de Cervelló, hermana del anterior, que procesó a un colono de su quadra de Torrelles a causa de un supuesto incesto ${ }^{98}$; Guillem Sala, mercader ultramarino, culpable de apoderarse fraudulentamente de un cargamento de lana que transportaba en una de sus naus"; el ya conocido Bernat Soler, ecónomo del monasterio de Sant Pere de les Puelles, que malversó parte de los fondos de la caja de la comunidad ${ }^{100}$; Guillem Martorell, beneficiado en la Sede barcelonesa, que guardó para sí parte del importe del laudemio perteneciente al altar de Santa Tecla ${ }^{101}$; y, finalmente, el miles Guillem de Viladecavalls, que expolió de su yunta de bueyes a unos campesinos de Piera cuando transitaban por un camino vecinal, en el transcurso de la guerra entre Ramon Folc de Cardona y Guillema de Montcada ${ }^{102}$.

Estos casos patentes de violencia y fraude, junto al reconocimiento de las pequeñas deudas domésticas, constituyen un verdadero exponente de la necesidad que siente la población ante la inminencia de la muerte, necesidad que se traduce en el miedo y la angustia de encontrar cerrado el acceso al Paraíso. Para mejorar su imagen, estos barceloneses de las primeras décadas del siglo XIV, no sólo confiesan su delito, sino que se lanzan a una desenfrenada carrera para redimir su culpa que se traduce en la liberalidad post mortem y así los muestra la documentación instituyendo misas, celebrando aniversarios, dotando económicamente a clérigos y muchachas sin recursos, ayudando a los hospitales de la ciudad, declarando herederos universales a los pobres de Jesucristo, legando fondos a los mercedarios para que rescaten a sus

\footnotetext{
que puedan identificar al acreedor, como Sibil.la Oliveres, domiciliada en la calle de Jutglar, que manifiesta deber 9 ss. a una panadera de Terrassa por 1 cuartera de harina de trigo que le compró, así como 7 ss. y 8 ds. a una harinera llamada Fuster que vive junto al Palau Reial, además de sentirse obligada a confesar que retiene en su poder una manta de lana que recibió de cierto campesino como garantía de un préstamo de 5 ss. [ACB, N, BV, MT, f.1r]. 96 lbidem, ff. 67v-70r.

97 lbidem, ff. 103r-106r.

98 lbidem, ff. $29 v-32 r$.

99 Además declara que dispuso de los bienes dotalicios de su mujer y del violario que adquirió para ella [lbidem, ff. 125r-129r].

100 Ibidem, ff. 72v-75v.

101 lbidem, ff. 148r-150r.

102 lbidem, ff. $64 \mathrm{v}-67 \mathrm{v}$.
} 
conciudadanos cautivos y realizando, en fin, cuantiosos desembolsos, con lo cual confían en que el juicio divino no será excesivamente riguroso.

Los frares mendicantes, dotados de una gran ascendencia espiritual sobre el grueso de la población, fomentan esta generosidad y recuerdan constantemente a las gentes que todos son iguales ante la muerte, canalizando a menudo la fortuna de los barceloneses en su propio beneficio. La declaración de deudas se inserta, sin duda, en este contexto y obedece en parte a motivos de conciencia, pasando así a formar parte de la mentalidad colectiva de los individuos.

\section{CONCLUSIONES}

La idea de la muerte, y sobre todo del más allá, golpea sin cesar la mente de los barceloneses, lo cual no deja de ser un fenómeno generalizado en todo el Occidente bajomedieval. La población de la Ciudad Condal se muestra preocupada, casi hasta la obsesión, ante el pensamiento de morir en pecado y perderse, así, en los horrores del infierno. Esta fijación les lleva a confesar culpas y tropelías cometidas a lo largo de la vida, poniendo especial interés en conseguir la redención mediante la limosna y la oración, mediante la caridad o la asistencia a los desvalidos y, en definitiva, mediante la purificación póstuma del alma. La desaparición física del individuo está siempre presente en el espíritu de ricos o pobres, menestrales o milites, banqueros o campesinos y, con una rara coincidencia de intereses, todos procuran mitigar sus efectos sobrenaturales a través de un proceso de autoinculpación que genera una serie de actos de verdadera liberalidad testamentaria.

No es de extrañar, pues, que las diferencias sociales que separan a los ciudadanos en vida se minimicen a la hora de manifestar las últimas voluntades. La fuerte estratificación social, basada en torno al poder y el dinero, que marca las pautas de conducta a seguir e imprime el carácter de pertenencia a un estamento determinado, se difuminan de manera ostensible en el plano anímico cuando llega el momento de enfrentarse a la posibilidad de la condenación.

La uniformidad de las manifestaciones expiatorias de los barceloneses es digna de atención. El comportamiento colectivo queda reflejado en el destino de sus bienes, en sus reacciones ante la gran gama de limosnas y obras pías de que disponen, constantemente propiciadas por la Iglesia (aniversarios, presbiteratos, legados a centros religiosos, etc.) y por la Corona o los regidores municipales (construcción de puentes, murallas, etc.). El único factor diferenciador será la capacidad económica, que se materializa en la entidad de los legados testamentarios y en su mayor o menor aceptación por parte de los diversos grupos sociolaborales, pero el rango que cada uno ocupa en la vida ciudadana dejará de ser impositivo y el individuo se verá libre de presiones sociales, llegado el momento de elegir sus propios canales de financiación espiritual, para superar satisfactoriamente el tránsito al más allá.

Esta mentalidad colectiva adquiere una gran trascendencia en el contexto de la Barcelona del primer tercio del siglo XIV, donde una jerarquizada población de casi 30.000 habitantes se desenvuelve en una superficie de $1.311 .200 \mathrm{~m}^{2}$ y vive las 
consecuencias de una reactivación generalizada de la economía ${ }^{103}$. El auge de ciertos sectores manufactureros, por una parte, y el volumen alcanzado por las mercancías circulantes, por el otro, van a propiciar la afirmación de la ciudadanía en cuanto burguesía diferenciada por la posesión de bienes y por su participación en los grupos de influencia. Pero, en cambio, el estamento de la nobleza permanece inmutable, con unas estructuras ancladas en un pasado de corte feudal que chocan a menudo con los intereses y nuevas necesidades de la menestralía y de los propios Consellers.

Es cierto que la gran masa humana que compone la población de Barcelona, junto a aquellos que se integran en las actividades propias del sector primario, se presenta fuertemente estratificada, pero aceptar la clásica división de la sociedad en razón a la pertenencia a uno u otro de los tres estamentos tradicionales resulta excesivamente simple, ya que la burguesía de principios del siglo XIV se halla tan jerarquizada como la misma nobleza y, de hecho, algunos de sus miembros poseen mayor fortuna y poder político que los propios milites. En realidad, la burguesía es un grupo dotado de cierta movilidad, ya que se puede salir por la cúspide y acceder así a las bases inferiores del estamento de la nobleza -caso de algunos mercaderes ultramarinos y hombres de negocios-, lo cual constituye un fenómeno nuevo que no es sino la culminación de un proceso que tiene su punto de partida a mediados del siglo anterior.

Así pues, algo ha cambiado respecto a tiempos anteriores y es la oportunidad de triunfar individualmente, a costa de grandes sacrificios y dedicación, e ingresar en las capas superiores de la pirámide social. Esta posibilidad está reservada a muy pocos, pero algunos cambistas o mercaderes que aparecen en la documentación no tienen nada que envidiar a los milites segundones, cuya única posibilidad de ascenso responde generalmente a la prestación de su brazo armado en las campañas militares de la Corona. Por otra parte, las diferencias que se observan en el seno de la burguesía -muy marcadas en la relación de bienes de los testamentos- parecen infranqueables y establecen auténticas barreras entre los ciudadanos, lo cual refuerza la inconveniencia de tratarlos conjuntamente como miembros de un estamento social homogéneo.

En las estructuras de la Iglesia, pese al inmovilismo y la mentalidad señorial de algunas jerarquías, también se aprecian cambios substanciales pues junto al clero regular empiezan a proliferar las comunidades religiosas urbanas, mezcladas con la población y agrupadas en torno al capítulo. Especial incidencia tendrá, en este sentido, la irrupción de las Órdenes Mendicantes en la vida ciudadana, hasta el extremo de que algunas de ellas sabrán conectar rápidamente con la mentalidad de la burguesía adinerada y acabarán acumulando riquezas y bienes materiales que harán olvidar en parte sus postulados iniciales de pobreza y predicación.

En este contexto social y humano se desarrolla la lucha del ciudadano contra la condenación eterna. Una lucha que, por su manifiesta trascendencia, equipara las pretensiones de los componentes de los diversos sectores sociales, anula barreras y

103 Datos aportados por Josefa Mutgé respecto a la época de Alfonso el Benigno [La ciudad de Barcelona durante el reinado de Alfonso el Benigno (1327-1336), Barcelona, CSIC, 1987, p. 2]. 
tiende, en definitiva, a homogeneizar las actitudes mentales de los barceloneses del primer tercio del siglo XIV.

JOSÉ-RAMÓN JULIÁ VIÑAMATA

Departamento de Historia Medieval

(Universidad de Barcelona) 